\title{
A Statistical Approach to Determine Optimal Models for IUPAC-Classified Adsorption Isotherms
}

\author{
Md. Matiar Rahman 1,2,3, Mahbubul Muttakin ${ }^{2}$, Animesh Pal ${ }^{2,4}{ }^{\mathbb{D}}$, Abu Zar Shafiullah ${ }^{5}$ and \\ Bidyut Baran Saha $1,2, *$ (D) \\ 1 Mechanical Engineering Department, Kyushu University, 744 Motooka, Nishi-ku, Fukuoka 819-0395, Japan; \\ matiar@du.ac.bd \\ 2 International Institute for Carbon-Neutral Energy Research (WPI-I2CNER), Kyushu University, 744 Motooka, \\ Nishi-ku, Fukuoka 819-0395, Japan; mahbubul.muttakin@gmail.com (M.M.); animesh@kyudai.jp (A.P.) \\ 3 Department of Statistics, University of Dhaka, Dhaka 1000, Bangladesh \\ Department of Nuclear Engineering, University of Dhaka, Dhaka 1000, Bangladesh \\ 5 Department of Statistics, University of Auckland, Auckland 1010, New Zealand; asha902@aucklanduni.ac.nz \\ * Correspondence: saha.baran.bidyut.213@m.kyushu-u.ac.jp; Tel.: +81-92-802-6722
}

Received: 15 October 2019; Accepted: 27 November 2019; Published: 29 November 2019

\begin{abstract}
Adsorption heat transformation (AHT) systems can play a major role in protecting our environment by decreasing the usage of fossil fuels and utilizing natural and alternative working fluids. The adsorption isotherm is the most important feature in characterizing an AHT system. There are eight types of International Union of Pure and Applied Chemistry (IUPAC) classified adsorption isotherms for different "adsorbent-adsorbate" pairs with numerous empirical or semi-empirical mathematical models to fit them. Researchers face difficulties in choosing the best isotherm model to describe their experimental findings as there are several models for a single type of adsorption isotherm. This study presents the optimal models for all eight types of isotherms employing several useful statistical approaches such as average error; confidence interval (CI), information criterion (ICs), and proportion tests using bootstrap sampling. Isotherm data of 13 working pairs (which include all eight types of IUPAC isotherms) for AHT applications are extracted from literature and fitted with appropriate models using two error functions. It was found that modified Brunauer-Emmet-Teller (BET) for Type-I(a) and Type-II; Tóth for Type-I(b); GAB for Type-III; Ng et al. model for Type-IV(a) and Type-IV(b); Sun and Chakraborty model for Type-V; and Yahia et al. model for Type-VI are the most appropriate as they ensure less information loss compared to other models. Moreover; the findings are affirmed using selection probability; overall; and pairwise proportion tests. The present findings are important in the rigorous analysis of isotherm data.
\end{abstract}

Keywords: bootstrap sample; information criterion; isotherm model; IUPAC; optimum isotherm

\section{Introduction}

To reduce global electricity demand, scientists are paying considerable attention to adsorption heat transformation (AHT) technologies such as cooling and heating as they can be driven by renewable energy or waste heat having a temperature of as low as $60^{\circ} \mathrm{C}$ [1]. Waste heat [2-6] or heat from cost-effective non-concentrating solar thermal collectors [7-10] can be utilized for this purpose. The principal component of anAHT system is its adsorption chamber, which is a heat exchanger in which the adsorbent materials are placed. The chamber goes through adsorption and desorption processes in cycles to provide thermal compression of the working fluid or adsorbate vapor. The significant factor affecting the performance of AHT is the "adsorbent-adsorbate" pair [11,12]. The fundamental characteristics of the "adsorbent-adsorbate" pair can be found by analyzing adsorption isotherm and 
kinetic models. The parameter values of the optimal isotherm model are needed for further analysis, like system design or simulation.

An adsorption isotherm provides information about the maximum amount of adsorbate that can be absorbed by the adsorbent at a particular pressure. In order to standardize experimental data of different "adsorbent-adsorbate" pairs, it is essential to correlate them with different isotherm models. Based on the nature of adsorption isotherms, the International Union of Pure and Applied Chemistry (IUPAC) $[13,14]$ classifies adsorption pairs into eight different types, as can be seen in Figure 1. Type-I(a) isotherm is found for narrow microporous adsorbent having a pore size $<\sim 1 \mathrm{~nm}$. The Type-I(b) isotherm is mainly characterized by monolayer adsorption. The uptake continuously increases with pressure and reaches a plateau at saturation pressure. Type-II isotherm is characterized by multilayer adsorption [15] and nearly analogous to the Type-I(b) shape; the only difference between the two is the absence of the plateau in Type-II. The uptake continuously increases even when the pressure ratio is close to unity. The shape of the Type-III adsorption isotherm is convex $[15,16]$. At low pressures, the uptake is low, but it increases sharply at high pressures. Depending on the pore width, Type-IV isotherm is divided into two types, one with hysteresis and another without hysteresis, i.e., Type-IV(a) (pore width greater than $4 \mathrm{~nm}$ ) and Type-IV(b) (pore width smaller than $4 \mathrm{~nm}$ ), respectively. Type-IV(b) is observed for the adsorbent having cylindrical and conical mesoporous with a smaller width, which is entirely reversible closed at the tapered end. Type- $\mathrm{V}$ is distinguished by its characteristic S-shaped isotherm, and it also demonstrates a hysteresis loop. Finally, in Type-VI, the adsorption occurs in steps.

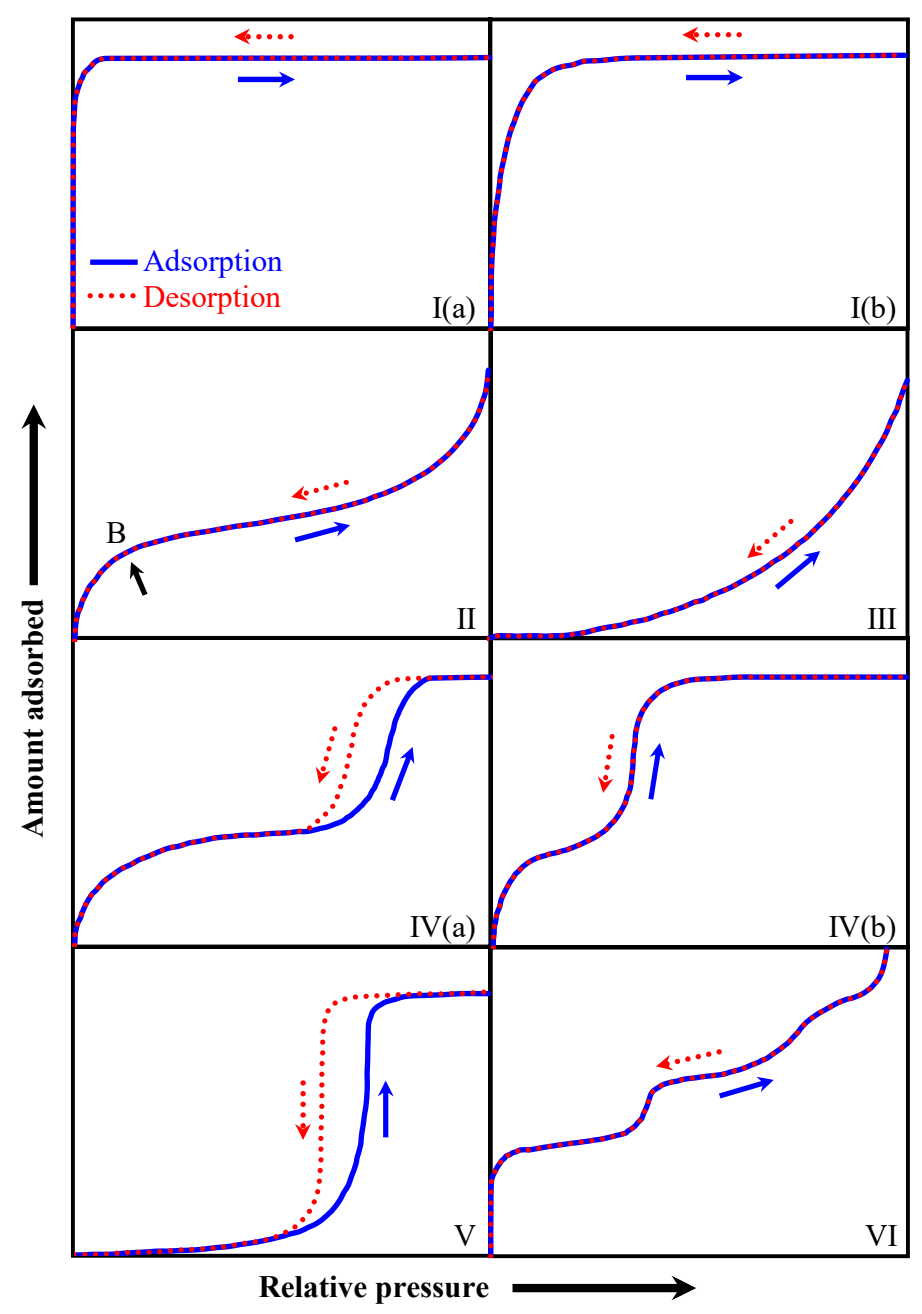

Figure 1. Physisorption isotherms classification (C2015 IUPAC) [14]. monolayer formation. 
Generally, isotherm data are correlated by applying various isotherm models where the bestfitted model is used to analyze the adsorption behavior. From the literature studies, it is found that different pairs exhibit different types of adsorption isotherms, and numerous authors had tried to get the best-fitted model for those [17]. Table 1 summarizes the different adsorption pairs with their isotherm type and the fitted model.

Table 1. Examples of adsorption pair to correspond isotherm type and the fitted model. BIDC: benzimidazole-derived carbons.

\begin{tabular}{|c|c|c|c|}
\hline Adsorption Pair & Type & Best Fitted Model & Reference \\
\hline $\begin{array}{l}\text { (i) Carbon } \mathrm{K} 4-700 / \mathrm{N}_{2} \text { at } 77 \mathrm{~K} \\
\text { (ii) BIDC-1-700/Ar at } 87 \mathrm{~K} \text { (pore size less than } 1 \\
\text { nm for both (i) and (ii)). }\end{array}$ & Type-I(a) & Fitted model is not available & $\begin{array}{l}\text { (i) Hu et al. [18] } \\
\text { (ii) Cychosz et al. [19] }\end{array}$ \\
\hline $\begin{array}{l}\text { (i) Maxsorb III/ethanol } \\
\text { (ii) Silica gel/water } \\
\text { (iii) Carbon based composite/CO } \mathrm{CO}_{2} \\
\text { (iv) Carbon based composite/CO } \\
\text { (v) WPT-AC/ethanol } \\
\text { (vi) M-AC/ethanol } \\
\text { (vii) Zeolite/water at } 25^{\circ} \mathrm{C} \\
\text { (viii) (SRD } 1352 / 3, \mathrm{FR} 20, \mathrm{ATO} \text { and } \\
\text { AP4-60/COCL-1200)/ } \mathrm{N}_{2}{ }^{*} \\
\text { (ix) Ionic liquid binder based composite/ethanol } \\
\text { (x) Silica gel based composite/water }\end{array}$ & Type-I(b) & $\begin{array}{l}\text { (i) D-A model } \\
\text { (ii) Tóth } \\
\text { (iii) Tóth } \\
\text { (iv) D-A and Tóth } \\
\text { (v) D-A and Tóth } \\
\text { (vi) D-A and Tóth } \\
\text { (vii) Tóth } \\
\text { (viii) D-A } \\
\text { (ix) D-A } \\
\text { (x) Tóth }\end{array}$ & $\begin{array}{l}\text { (i) El-Sharkawy et al. [20] } \\
\text { (ii) Rahman et al. [21] } \\
\text { (iii) Pal et al. [22] } \\
\text { (iv) Berdenova et al. [23] } \\
\text { (v) Pal et al. [24,25] } \\
\text { (vi) Pal et al. [24,25] } \\
\text { (vii) Wang et al. [26] } \\
\text { (viii) Brancato et al. [27] } \\
\text { (ix) Pal et al. [28] } \\
\text { (x) Younes et al. [29] }\end{array}$ \\
\hline $\begin{array}{l}\text { (i) } \mathrm{PBA} / \text { water at } 25^{\circ} \mathrm{C} \\
\text { (ii) Alumina/water at } 20^{\circ} \mathrm{C} \\
\text { (iii) } \mathrm{PCB} / \text { water at } 22^{\circ} \mathrm{C}\end{array}$ & Type-II & $\begin{array}{l}\text { (i) GAB model } \\
\text { (ii) BET model } \\
\text { (iii) Not fitted }\end{array}$ & $\begin{array}{l}\text { (i) Sultan et al. [30] } \\
\text { (ii) Naono et al. [31] } \\
\text { (iii) Wang et al. [32] }\end{array}$ \\
\hline $\begin{array}{l}\text { (i) } \mathrm{ACP} / \text { water at } 30^{\circ} \mathrm{C} \\
\text { (ii) Dried fruits/moisture }\end{array}$ & Type-III & $\begin{array}{l}\text { (i) D-A model } \\
\text { (ii) GAB model }\end{array}$ & $\begin{array}{l}\text { (i) Sultan et al. [30] } \\
\text { (ii) Maroulis et al. [33] }\end{array}$ \\
\hline $\begin{array}{l}\text { (i) Oxidized carbon/water } \\
\text { (ii) PVDC/water at } 35^{\circ} \mathrm{C} \\
\text { iii) Tripolis/water at } 21^{\circ} \mathrm{C}\end{array}$ & Type-IV(a) & $\begin{array}{l}\text { (i) Do et al. model } \\
\text { (ii) Do et al. model } \\
\text { (iii) BET model }\end{array}$ & $\begin{array}{l}\text { (i) Do et al. [34] } \\
\text { (ii) Do et al. [34] } \\
\text { (iii) Rakitskaya et al. [35] }\end{array}$ \\
\hline $\begin{array}{l}\text { (i) IRMOF-74-V-hex/argon at } 87 \mathrm{~K} \\
\text { (ii) IRMOF-74-V-hex/nitrogen at } 77 \mathrm{~K} \text { (pore size } \\
\text { less than } 4 \mathrm{~nm} \text { ) }\end{array}$ & Type-IV(b) & The fitted model is not available & $\begin{array}{l}\text { (i) Cho et al. [36] } \\
\text { (ii) Cho et al. [36] }\end{array}$ \\
\hline $\begin{array}{l}\text { (i) ACF/water at } 30^{\circ} \mathrm{C} \\
\text { (ii) Hydrophobic carbon/water } \\
\text { (iii) AQSOA-Z01/water and AQSOA-Z02/water } \\
\text { (iv) Ferroaluminophosphate/water } \\
\text { (v) AQSOA zeolite/ water } \\
\text { (vi) AlPO-18, FAPO-34, SAPO-34/water }\end{array}$ & Type-V & $\begin{array}{l}\text { (i) D-A model } \\
\text { (ii) Do et al. model } \\
\text { (iii) D-A, modified Langmuir } \\
\text { (iv) Hybrid model } \\
\text { (v) D-A, modified Langmuir, } \\
\text { Sun and Chakraborty } \\
\text { (vi) D-A model }\end{array}$ & $\begin{array}{l}\text { (i) Sultan et al. [30] } \\
\text { (ii) Do et al. [34] } \\
\text { (iii) Kayal et al. [37] } \\
\text { (iv) Kim et al. [38] } \\
\text { (v) Teo et al. [39] } \\
\text { (vi) Brancato et al. [40] }\end{array}$ \\
\hline $\begin{array}{l}\text { (i) } \mathrm{MgO}(100) / \text { methane } \\
\text { (ii) Exfoliated graphite/methane }\end{array}$ & Type-VI & $\begin{array}{l}\text { (i) } \mathrm{Ng} \text { et al. model } \\
\text { (ii) Yahia et al. model }\end{array}$ & $\begin{array}{l}\text { (i) Ng et al. [16] } \\
\text { (ii) Yahia et al. [41] }\end{array}$ \\
\hline
\end{tabular}

* Activated carbon from various biomass sources.

Thus, from the above literature reviews, it is evident that many adsorption isotherm models had been suggested for different types of IUPAC classified isotherms, but there is no widely accepted model for any specific isotherm type. Moreover, there is no model fitted yet for Type-I(a) and Type-IV(b) isotherm. Furthermore, there is also a lack of explanation about the determination of the most suitable model for any type of adsorption isotherm considering the statistical analysis of the best-fitted model. In almost all the cases, to the best of our knowledge, authors did not consider the information loss of the fitted model, and they used only root mean square deviation (RMSD) error analysis in their investigations. RMSD does not even consider the number of parameters of the fitted model. Besides, different scientists proposed several models for a particular type of isotherm. For example, authors [42] proposed D-A, Tóth, Langmuir, Modified D-A for Type-I(b). Firstly, several models are fitted by the researcher for specific experimental data, and then based on RMSD, the researcher makes a decision for the optimal model, which is tedious work. The main aim of the current study is to find out optimal 
models for all the eight types of isotherms employing several statistical tools such as average error, confidence interval (CI), information criterion (IC's), and proportion tests using bootstrap sampling. In the current study, two error functions, RMSD and hybrid fractional error deviation (HYBRID) used to optimize the parameters for Type-I(a) and Type-I(b) adsorption isotherm. Whereas, on the other hand only HYBRID error evaluation function is used for other types since authors [21] showed that HYBRID error was better than other errors for optimization of parameters. Parameter effect adjustment and information loss are considered in this investigation to find the optimal isotherm model for a particular type, which also makes it significant from the statistical analysis of the best-fitting model.

In this study, 13 relevant isotherm data of "adsorbent-adsorbate" pairs are extracted from the literature for identifying optimal models for IUPAC classified eight types of isotherms. Statistical information criteria using a bootstrap sample have been used to select the optimal isotherm model for all IUPAC classified adsorption isotherms. Section 2 of this article describes different isotherm models and the corresponding equations used in this study. Error evaluation functions and descriptions of statistical tools are narrated in Sections 3 and 4, respectively. In R-programming, 1000 (large sample size) bootstrap samples $(n=1000)$ are taken, and the distribution of $n=1000$ bootstrap errors is constructed to validate the use of model selection criteria, which are used for finding the optimal isotherm model. The probability of optimal model selections is also calculated. Finally, overall and pairwise proportion tests are conducted, for the equality of minimum information criterion, to identify the statistically significant optimal models for all types of IUPAC classified isotherms.

\section{Adsorption Isotherm Models}

The maximum amount of adsorbate that can be adsorbed by the adsorbent at specific pressure and temperature is known as the equilibrium uptake. This equilibrium uptake at a particular temperature can be represented by an isotherm model that shows the change in uptake with pressure. Various isotherm models are given by scientists to simulate the adsorption characteristics of different adsorption pairs.

\subsection{Dubinin-Astakhov (D-A) Model}

The Dubinin-Astakhov (D-A) model [43] is widely used in the adsorption of water and several gases on carbon-based adsorbent [25]. Carbonaceous solids resulting from a high degree of burn-off during activation; for these consequences, heterogeneity increases; in this case, the D-A model is used [44]. The model can be expressed by,

$$
\frac{W}{W_{0}}=\exp \left[-\left\{\frac{R T}{E} \ln \left(\frac{P_{s}}{P}\right)\right\}^{n}\right]
$$

where, $W$ is the instantaneous uptake in $[\mathrm{g} / \mathrm{g}], W_{0}$ denotes maximum uptake $[\mathrm{g} / \mathrm{g}], E$ is the characteristic energy $[\mathrm{kJ} / \mathrm{mol}]$ and $n$ is the heterogeneity parameter [-]. P is the pressure $[\mathrm{kPa}]$, and $P_{S}$ denotes saturated vapor pressure [kPa]. When $n=2$, the $\mathrm{D}-\mathrm{A}$ model reduces to the Dubinin-Radushkevic (D-R) model.

\subsection{Modified Dubinin-Astakhov (D-A) Model}

In the D-A model, $P_{S}$ denotes the saturated vapor pressure at temperature $T$. The critical point, $T_{c}$ of $\mathrm{CO}_{2}$ is $31^{\circ} \mathrm{C}$. So above this point, the liquid state does not exist. In such a case, the saturated vapor pressure is replaced by the pseudo saturated vapor pressure determined by $[45,46]$,

$$
P_{s}=\left(\frac{T}{T_{c}}\right)^{k} P_{c}
$$


where $k$ is the parameter indicating the interaction between adsorbate and adsorbent. The modified D-A model can be written as,

$$
q=\frac{W_{0}}{V_{m}} \exp \left[-\left\{\frac{R T}{E} \ln \left(\frac{P_{s}}{P}\right)\right\}^{n}\right]
$$

where $q$ is the instantaneous adsorbed phase volume $\left(\mathrm{cm}^{3} / \mathrm{g}\right), W_{0}$ denotes maximum micropore volume $\left(\mathrm{cm}^{3} / \mathrm{g}\right)$. The molar volume $V_{m}$ of the adsorbed phase is estimated using properties of $\mathrm{CO}_{2}$ at triple point and coefficient of thermal expansion which is given by Ozawa et al. [47],

$$
V_{m}=V_{t} \exp \left[\alpha\left(T-T_{t}\right)\right]
$$

where $T_{t}$ and $V_{t}$ denote temperatures and molar volume of the liquid adsorbate at the triple point, respectively, $\alpha$ is the thermal expansion coefficient of the superheated liquid and $\alpha=\frac{1}{T}$. For $\mathrm{CO}_{2}$ adsorption onto activated carbon, the values observed are $V_{t}=0.84858 \mathrm{~cm}^{3} / \mathrm{g}, T_{t}=216.6 \mathrm{~K}$ and $\alpha=0.0025 \frac{1}{K}[48]$.

\subsection{Tóth Model}

The Tóth model [42] performs well in estimating the adsorption uptake both in low pressure and in high-pressure regions. It describes well many systems with sub-monolayer coverage. It can be expressed by,

$$
\frac{W}{W_{0}}=\frac{b_{0} e^{\frac{Q}{R T} P}}{\left[1+\left(b_{0} e^{\frac{Q}{R T}} P\right)^{t}\right]^{\frac{1}{t}}}
$$

where $b_{0}$ is the equilibrium constant $[1 / \mathrm{kPa}], Q$ is the isosteric heat of adsorption $[\mathrm{J} / \mathrm{mol}]$, and $R$ is universal gas constant $[\mathrm{J} /(\mathrm{mol} . \mathrm{K})]$. The parameter $t$ is supposed to characterize the system heterogeneity. If it deviates further from unity, the system is said to be more heterogeneous [44].

\subsection{Langmuir Model}

The Langmuir model [49] assumes that all sites of adsorbents are energetically equivalent and identical, i.e., homogeneous, and each site is occupied only by one atom [44]. It can explain well the monolayer adsorption process. When $t=1$, the Tóth model reduces to the Langmuir model and can be expressed as,

$$
\frac{W}{W_{0}}=\frac{b_{0} e^{\frac{Q}{R T}} P}{1+b_{0} e^{\frac{Q}{R T}} P}
$$

\subsection{Modified Langmuir Model}

The Modified Langmuir model [37,50] was developed based on the Fermi-Dirac distribution function that includes the interaction between refrigerant and adsorbent, loading, and surface heterogeneity factors. It can be described by,

$$
\frac{W}{W_{0}}=\frac{\beta\left(\frac{P}{\varphi^{*}}\right)}{\left[1+\left(\beta^{m}-\alpha\right)\left(\frac{P}{\varphi^{*}}\right)^{m}\right]^{\frac{1}{m}}}
$$

where, $\frac{P}{\varphi^{*}}=\left(\frac{P}{P_{s}}\right) \exp \left\{\frac{\phi_{m}}{R T}\left\{1-\left(\frac{P}{P_{s}}\right)^{n}\right\}+z\right\}$.

where, $\beta$ is load factor [-], $z$ is compressibility factor $[-], \alpha$ is a coefficient $[-], \phi_{m}$ is minimum potential energy $[\mathrm{J} / \mathrm{mol}], m$ is heterogeneity factor or mass $[\mathrm{kg}]$ and $n$ is adsorbate-adsorbent interaction factor $[-]$. 


\subsection{Freundlich Model}

The Freundlich model $[24,51]$ is the most primitive model that describes the adsorption mechanism and assumes that the surface is heterogeneous for energy distribution; also, surface topography is patchwise [44]. It can be written as,

$$
\frac{W}{W_{0}}=\left(\frac{P}{P_{s}}\right)^{\frac{1}{n}}
$$

Generally, the parameter $n$ is greater than unity [44]. Freundlich model turns into Henry's law if $n=1$, which works very well to simulate the adsorption uptake in the low-pressure region.

\subsection{Hill Model}

The binding capability of the different gas molecules onto homogeneous adsorbent can be described by the Hill model. The model adopts that adsorption is a cooperative phenomenon, with the ligand-binding capacity at one site on the macromolecule, which may impetus different binding sites on the same macromolecule [52]. It is a three-parameter model that combines properties of Langmuir and Freundlich isotherms and can be expressed as,

$$
\frac{W}{W_{0}}=\frac{\left(\frac{P}{P_{s}}\right)^{n_{H}}}{K_{D}+\left(\frac{P}{P_{s}}\right)^{n_{H}}}
$$

where, $n_{H}$ and $K_{D}$ represent the Hill cooperativity coefficient of the binding interaction [-] and Hill constant [-] respectively. Here $n_{H}>1$ indicates positive binding, $n_{H}=1$ is used for non-cooperative binding and $n_{H}<1$ indicates negative cooperativity in binding.

\subsection{Mahle Model}

The Type-V adsorption isotherm is characterized by its typical S-shape. It assumes to describe a pore scattering that would be occupied by capillary condensation. Mahle [53] developed a model that explains a Type-V adsorption isotherm. It can be expressed as,

$$
\frac{W}{W_{s}}=\frac{1}{C}\left[\tan ^{-1}\left(\frac{x-A}{B}\right)-\tan ^{-1}\left(\frac{-A}{B}\right)\right]
$$

where, $C=\tan ^{-1}\left(\frac{1-A}{B}\right)-\tan ^{-1}\left(\frac{-A}{B}\right), A=\exp \left(A_{0}+\frac{A_{1}}{T}\right)$ is the locus of the maximum of the distribution function in terms of relative humidity. So, the adsorption uptake depends on three parameters $A_{0}, A_{1}, B$ and saturation uptake $W_{s}[\mathrm{~g} / \mathrm{g}]$.

\subsection{Brunauer-Emmet-Teller (BET) Model}

The Brunauer-Emmet-Teller (BET) model is developed to explain multilayer adsorption and is most widely used in the characterization of porous materials. The assumptions of the theory are the same as those used in Langmuir's theory. It is assumed that the interaction energy between solid and molecule of the first layer is higher than the heat of vaporization. The heat of adsorption of the second and subsequent layers are the same and equal to the heat of liquefaction [44]. The BET model is given by,

$$
\frac{V}{V_{m}}=\frac{C x}{(1-x)(1-x+C x)}
$$

where $x$ is the pressure ratio $x=\frac{P}{P_{0}}, V$ is the amount of total gas adsorbed $\left[\mathrm{m}^{3}\right], V_{m}$ is the monolayer coverage [nm]. The parameter $C$ depends on the exponential of the difference between the adsorption energy of the first layer and the heat of liquefaction [-]. The larger the value of $C$, the sooner is the multilayer formation, and the convexity of the isotherm increases toward the low-pressure range. 


\subsection{Modified BET Model}

The BET model is unable to explain the adsorption uptake near saturation pressure since with $x=1$, and uptake becomes infinite. It assumes that adsorption heat of the second layer and the next several layers being less than the heat of liquefaction [44]. The model is thus modified by introducing a parameter $K$, and the modified model takes the form,

$$
\frac{V}{V_{m}}=\frac{C K x}{(1-K x)\{(1+(C-1) K x)\}}
$$

If $K=1$, the modified BET model becomes the classical BET model.

\subsection{Guggenheim-Anderson-De Boer (GAB) Model}

The Guggenheim-Anderson-De Boer (GAB) model [33] is also a modification of the BET model and is used for the fitting of type III adsorption isotherm. It can be described by,

$$
\frac{V}{V_{m}}=\frac{C K x}{(1-K x)\{1+(C-1) K x\}}
$$

where, $C$ and $K$ are constant parameters related to the temperature of following equations, $C=C_{0} \exp \left(\frac{\Delta H_{1}}{R T}\right)$ and $K=K_{0} \exp \left(\frac{\Delta H_{2}}{R T}\right) ;$ and $\Delta H_{1}=H_{m}-H_{n}, \Delta H_{2}=H_{1}-H_{n}$ are the functions of the heat of adsorption. $H_{m}$ and $H_{n}$ are the heat of adsorption for monolayer and multilayer adsorption of water.

\subsection{Sun and Chakraborty Model}

Sun and Chakraborty [54] developed a model that can explain well the S-shaped isotherms. The model can thermodynamically connect the adsorption uptake with the porous structure of the adsorbent material. The uptake is a function of isosteric heat of adsorption and depends on the adsorptive sites of the adsorbent materials. The model can be expressed by,

$$
\frac{W}{W_{0}}=\frac{K\left(\frac{P}{P_{s}}\right)^{m}}{1+(K-1)\left(\frac{P}{P_{s}}\right)^{m}}
$$

where $K=\alpha \exp \left[\frac{m\left(Q-h_{f g}\right)}{R T}\right] . Q$ is the isosteric heat of adsorption at zero surface coverage $[\mathrm{kJ} / \mathrm{kg}]$, and $h_{f g}$ is the enthalpy of evaporation $[\mathrm{kJ} / \mathrm{kg}]$.

\subsection{Hybrid Model (Henry + Sips)}

The hybrid model proposed by Kim et al. [38] comprising both the Henry and Sips isotherms includes nine parameters that are physically meaningful. The hybrid model is expressed as,

$$
q=\beta K_{H}\left(\frac{P}{P_{s}}\right)+(1-\beta) \frac{q_{m}\left(K_{s} P / P_{s}\right)^{1 / n}}{1+\left(K_{s} P / P_{s}\right)^{1 / n}}
$$

where $q$ and $q_{m}$ denote the absolute and maximum amount adsorbed. $n$ is the heterogeneity parameter determined by $n=A+\frac{B}{T}$. $A$ and $B$ are the parameters of heterogeneity $\beta=\exp \left(-\alpha \frac{P}{P_{s}}\right)$, where $\alpha$ is a function of temperature following relation $\alpha=K_{1}+K_{2} \frac{T}{T_{\text {ref }}}$. The reference temperature $T_{\text {ref }}=273.15 \mathrm{~K}$. The first term of the right- hand side of the Equation (15) is dominant in the low pressure or Henry region, and the last term takes dominance in the high-pressure region. $K$ is the Henry constant whose values for both the regions are determined from $K=K_{0} \exp \left(-\frac{\Delta H}{R T}\right)$, where $K_{0}$ is the pre-exponential factor of the Henry constant, and $\Delta H$ is the isosteric enthalpy of adsorption at zero loadings. 


\subsection{Ben Yahia Model}

The mathematical model developed by Yahia et al. [41], is used for the fitting of the Type-VI adsorption isotherm. They inferred that there could be two possibilities to explain the shape of this curve: energetic and geometric/stereographic. According to their assumptions, the energetic aspect is dominant, and there are four levels of energy present in the adsorption surface. The equation to determine the adsorbed quantity at equilibrium is expressed as,

$$
W=\frac{n_{1} N_{M 1}\left(\frac{P}{P_{1}}\right)^{n_{1}}}{1+\left(\frac{P}{P_{1}}\right)^{n^{1}}}+\frac{n_{2} N_{M 2}\left(\frac{P}{P_{2}}\right)^{n_{2}}}{1+\left(\frac{P}{P_{2}}\right)^{n^{2}}}+\frac{n_{3} N_{M 3}\left(\frac{P}{P_{3}}\right)^{n_{3}}}{1+\left(\frac{P}{P_{3}}\right)^{n^{3}}}+\frac{n_{4} N_{M 4}\left(\frac{P}{P_{4}}\right)^{n_{4}}}{1+\left(\frac{P}{P_{4}}\right)^{n^{4}}}
$$

with $i=1,2,3$, and 4, pressure $P_{i}$ can be expressed as, $P_{i}=P_{s} \exp \left(\frac{E_{a i}}{R T}\right) \cdot n_{i}$ is the number of molecules per site, $N_{m i}$ is the density of receptor sites, and $E_{a i}$ denotes the molar adsorption energy of gases in the site $i$.

\subsection{Universal Isotherm Model}

A universal isotherm model is proposed by $\mathrm{Ng}$ et al. [16], which assumed adsorbent with the heterogeneous surface where homogeneity is assumed in each site for energy level and which can be expressed by,

$$
\frac{q}{q^{*}}=\sum_{i=1}^{n} \alpha_{i}\left[\frac{\left(\frac{p}{p_{s}} \exp \left(\frac{\varepsilon_{o i}}{R T}\right)\right)^{\frac{R T}{m i}}}{1+\left(\frac{p}{p_{s}} \exp \left(\frac{\varepsilon_{o i}}{R T}\right)\right)^{\frac{R T}{m i}}}\right]_{i}
$$

where, $n=2$ indicates that two peaks can describe the energy distribution of the isotherm, which is valid for IUPAC classified isotherms from Type-I to Type-V having varied probability factors $\alpha_{1}$ and $\alpha_{2}$ where $\alpha_{1}+\alpha_{2}=1$. For Type-VI, the energy distribution function needs four peaks $(n=4)$ with probability factors $\alpha_{1}, \alpha_{2}, \alpha_{3}$, and $\alpha_{4}$, where $\alpha_{1}+\alpha_{2}+\alpha_{3}+\alpha_{4}=1$. $\varepsilon_{o i}$ is the adsorption energy site with maximum frequency and $m_{i}$ denotes the range of energy sites available for adsorption. In other words, they represent the mean and deviation of an energy term, respectively. The larger value of $m$ means high surface heterogeneity as well as the smaller slope of the model graph.

\section{Error Evaluation Function}

In this study, two error functions, namely the HYBRID and RMSD error functions, are used to optimize the parameters of the models. In our previous study [21], through analysis of the sum of normalized error (SNE), it was concluded that the HYBRID error function is appropriate to use for parameter optimization for almost all isotherm models. On the other hand, RMSD error function is frequently used by the researchers [21] for the optimization of parameters. Simultaneous use of these two error functions is considered in the current study for optimization since both of them are squared-type error function.

\subsection{Root Mean Square Deviation (RMSD)}

The most widely used error function used by the researchers is RMSD, which can be expressed as,

$$
\mathrm{RMSD}=\sqrt{\frac{\sum_{i=1}^{n}\left(W_{\text {experimental }}-W_{\text {calculated }}\right)_{i}^{2}}{n}}
$$

RMSD error function is used to estimate the parameters of the model, avoiding large error deviation between experimental data and the isotherm model. The error distribution of RMSD follows meso-kurtic, which is the assumption of least square regression fitting. 


\subsection{Hybrid Fractional Error Deviation (HYBRID)}

Assumptions of RMSD/SSE errors are unbiased, free from outliers, and errors follow normal distribution [55]. Some special cases do not follow these assumptions. For example, in a low-pressure region, experimental uptake is not found precisely. In this case, some errors (deviation from the model) are considered as outliers. On the other hand, if we increase the model parameters, better fitting is possible. However, it will increase the model complexity. So the effect of the number of parameters should be incorporated in the error evaluation function. Porter et al. [56] developed a new error evaluation function, known as hybrid error evaluation function and denoted by HYBRID in the current study, for improving the fit of low- pressure region. In the HYBRID error function, the parameter effect is considered. This HYBRID error evaluation function balances absolute deviation against fractional error. It can be expressed as,

$$
\text { HYBRID }=\frac{100}{n-p} * \sum_{i=1}^{n}\left[\frac{\left(W_{\text {calculated }}-W_{\text {experimental }}\right)^{2}}{W_{\text {experimental }}}\right]_{i}
$$

Here, $p$ is the number of parameters in the model, and $(n-p)$ is the degrees of freedom. HYBRID error evaluation function considers the number of parameters in the model. So, for the comparison of several models with an unequal number of parameters, the HYBRID error evaluation function is found to be more suitable than the RMSD error function.

\section{Statistical Tools}

In this section, we introduce the statistical techniques applied for selecting the best model(s) for the eight IUPAC-classified types of isotherms. These models are compared based on a number of model selection criteria discussed in Section 4.1. The selection criteria require estimating the residual sum of squares (RSS) for the candidate models, i.e., the sum of the squared differences between the observed and expected values of Y (uptake). However, given the model under study, the experimental data allows obtaining a single estimate of RSS, which in turn gives an estimate for each of the selection criteria. For deterministic (mathematical) models, one approach to drawing inference on the likelihood of selecting a model can be based on simulation studies (non-parametric methods). In the present context, a simulation-based approach generates samples repeatedly from the exiting data, since the actual experiment cannot be repeated many times due to time and economic constraints. We consider the bootstrap sampling approach (Section 4.2) for generating the repeated samples. Since our experiment was conducted under controlled conditions, the experimental outcomes are assumed to represent the underlying (non-existent) population. Thus, the simulated data are also assumed to represent the actual outcome for the corresponding treatment combinations. This allows comparing the candidate models a large number of times by estimating a selection criterion from each sample. The proportion of samples that correspond to a certain model having the minimum of a selection criterion among the candidate models gives an empirical estimate of the rate (likelihood) that the model is selected by the criterion for such experimental outcomes as in the current study. In this study, the likelihood of each model is estimated separately for each criterion, and statistical tests are carried out for finding evidence that certain model(s) may be more likely to be selected (better) than other models. The statistical tests include the overall proportion test and pairwise comparisons discussed in Section 4.3.

\subsection{Information-Based Criterion for Model Selection}

Given a dataset and a list of candidate models, one approach to selecting the best model is by estimating a model selection criterion. The commonly used criteria in the literature include the akaike information criterion (AIC), bayesian information criterion (BIC), and their extensions, which are called the information-based criteria (IC). The IC estimates a loss of information that the model incurs, as a measure of distance from the most parsimonious (true) model. Thus, the model with the lowest IC 
incurs the minimum information loss, hence selected as the parsimonious to the true model. In this study, a number of information criteria are applied separately for selecting the best candidate model among the candidates.

The information-based criteria consist of the goodness of fit term (maximized log-likelihood, $-2 l$ ) and a penalty term $f(n, p)$ for the complexity of the model. The penalty term $f(n, p)$ is a function of sample size $(n)$ and the number of parameters $(p)$, required for fitting the model [57-59]. Under Gaussian error, the term $-2 l$ can be expressed as $n(\log (2 \pi)+\log (R S S)+\log (n)+1)$, which indicates that for fixed $n$, the goodness of fit term is mainly a function of residual sum of squares. In general, the information-based model selection criteria take the form

$$
I C=-2 l+f(n, p)
$$

Akaika (1969) [60-62] proposed using $f(n, p)=2 p$ and suggests that the criterion AIC $=-2 l+2 p$ [58] minimizes the average Kulback-Leibler (K-L) distance (1951) [63] between the candidate model and the true model. It was found that the performances of AIC were poor if the number of parameters in the model is large compared to the sample size [59]. Considering the $\mathrm{K}-\mathrm{L}$ distance and maximized log-likelihood, different authors [64-66] recommended using corrected versions of AIC, which usually apply a slightly heavier penalty to the goodness of fit term. Sugiura [65] first derived a second-order alternative of AIC in which bias correction was added by Hurvich and Tsai [64]. Thus, a corrected version of $A I C$ namely, $A I C c$. If $n$ is large, compared to $p$, the correction terms $[n /(n-p-1)]$ is negligible; hence, the $A I C C$ and $A I C$ are equally efficient. In all other cases, it is recommended to use AIC [ [67]. Phoa et al. [68] recommended a modified version of $A I C$, i.e., $m A I C=-2 l+2 p^{2}$, which uses a quadratic penalty for model complexity instead of a linear penalty in AIC. In a Bayesian framework, Schwarz (1978) [69] proposed BIC $=-2 l+p \ln (n)$ [69] that uses Bayesian information and posterior probability. The form of BIC is similar to $A I C$ except that the penalty term $2 p$ is replaced by $\ln (n)$. Sclove (1987) [57] proposed adjusted BIC (denoted by ABIC), based on the information from Rissanen (1978) [70] and Boekee and Buss (1981) [71]. Here, the form of the penalty term is, $f(n, p)=p \ln [(n+2) / 24][21,47]$. Likewise, Bozdogan [61] proposed another modified version of BIC, namely CAIC using $f(n, p)=p[\ln (n)+1)$. More explanation of information-based criteria can be found in our previous study [21]. In this paper, the information criterion (IC) as mentioned above is applied separately for comparing the selection rates of the competing models. Since current experimental outputs allow only one estimate of each criterion for the competing models, we consider bootstrap samples to re-estimate the criteria many times and compared the likelihood of the models, separately for each criterion. Therefore, we have concluded our findings based on the decision of the majority of the ICs.

\subsection{Bootstrap Approach}

Efron and Tibshi-rani (1993) [72] introduced a bootstrap sampling method that can be used to perform data-based (non-parametric) statistical inference [73]. In this approach, the observed/experimental data are assumed to represent the underlying population, and new samples are generated by randomly selecting samples from the original sample (outcome) with replacement. Thus, an estimate of a parameter/metric or a hypothesis test can be obtained repeatedly based on random samples of the same size as the original sample. The estimates from the repeated samples generate an empirical sampling distribution as a straightforward non-parametric way to derive the standard errors and confidence intervals of complex parameters, such as percentile points, proportions, odds ratio, and correlation coefficients. In the present context, the parameter of interest is the residual sum of squares of the candidate models. The underlying idea of bootstrapping is that the inference about a population from sample data (sample $\rightarrow$ population) can be modeled by resampling the sample data and performing inference about a sample from resampled data (resampled $\rightarrow$ sample). 
In the context of the present study, the outcome of the experiments is the base sample, from which the observed estimates of RMSD/HYBRID (and the IC) for the candidate models. In practice, since it is usually not feasible to repeat an experiment large number of times, bootstrapping allows generating a large number of samples, so that the errors can be estimated repeatedly from these data sets. Here the $i$-th bootstrap sample $(i=1,2, \ldots, \mathrm{L})$ gives the $i$-th estimate of observed error, the RSSi $(i=1,2, . ., \mathrm{L})$ for the goodness of fit terms, which in turn is used to estimate the IC. In this study, L = 1000 is used as we believe that the number is large enough to generate the sampling distributions of the estimates. Using these bootstrap estimates, we thus test for significance of RSS and obtain interval estimates in a nonparametric approach.

\subsection{Bootstrap p-Value and Confidence Interval (CI) of Residual Sum of Squares (RSS)}

The bootstrap distribution of error allows finding the $p$-value and confidence interval of RSS. The confidence interval [55] gives a degree of certainty of an estimator since it is associated with a probability statement. If the same sampling technique is employed to draw different samples and $95 \%$ confidence interval is calculated, then the probability that the true parameter will fall in that interval is 0.95 . In this study, the $95 \%$ bootstrap confidence intervals (CIs) for the errors are obtained by discarding the $2.5 \%$ lower and $2.5 \%$ higher values of observed errors from the bootstrap distribution. The tail area in bootstrap distribution, starting from the observed RSS, gives $p$-value [21] for testing the significance of the error estimate.

Thus in a bootstrap approach, $p$-value refers to the proportion of bootstrap samples that correspond to the observed and more extreme values of observed error.

\subsection{Proportion Tests}

The bootstrap samples generate 1000 estimates of each IC, separately for each candidate model. For a certain criterion, the proportion of 1000 samples when a model archives the minimum value compared to other candidate models, is given by:

(Number of times the model attains minimum IC)/(1000 (number of bootstrap samples))

Using the bootstrap samples, since we estimate each IC separately for six (for example) candidate models, the models correspond to six proportions for a given criterion. The proportions are estimated rate or likelihood that the models are selected by the specific criterion. Since the proportions are bootstrap estimates of true likelihood, we perform a statistical test for the equality of the likelihoods.

Hypotheses (H0). The models are equally likely to be selected by the criterion.

vs.

Hypotheses (H1). They are not equally likely

A rejection of the hypothesis leads to pairwise comparisons of the proportions. These tests are conducted by applying a chi-square test and t-tests, respectively. Thus, a single or set of best models are identified SEPARATELY by each criterion.

\subsubsection{Chi-Squared Test for Equality of Proportions}

The Chi-squared test is an overall test for the equality of more than two proportions. For example, suppose a gambler wishes to test if the six numbers of a six-sided die are equally likely to appear on the top when the die is rolled. The gambler performs an experiment by rolling the die a large number (say 1000) of times and records the frequency $\left(O_{i}\right)$ that the $i$-th number $(i=1,2, \ldots, 6)$ appears on top out of the 1000 trials. Thus, the proportion $\hat{\pi}=\frac{O_{i}}{1000}$. If $P_{1}, P_{2}, \ldots, P_{6}$ denote the actual probability of occurrence of the six numbers, then the following hypotheses can be tested by applying the chi-squared test, 
Hypotheses (H0). $P_{1}=P_{2}=\ldots=P_{6}$

vs.

Hypotheses (H1). At least two are different

The test-statistic is given by,

$$
\chi^{2}=\sum_{i=1}^{6} \frac{\left(O_{i}-E_{i}\right)^{2}}{E_{i}}
$$

where $O_{i}$ refers to the observed frequency and $E_{i}=(1 / 6),{ }^{*} L$ refers to the expected frequency of i-th number in the 1000 trials under the assumption that $H_{0}$ is true. The test statistic is chi-square distribution with 5 degrees of freedom. The overall proportion test rejects $H_{0}$ in favor of $H_{1}$ if the $p$-value is less than the significance level $\alpha=0.05$.

As with the above example, in this study, we have six candidate models. For each bootstrap sample, errors are obtained for different models; IC's are calculated based on the errors, and the model that attains the minimum of an IC is recorded. Given IC, thus, the $L$ bootstrap samples give $O_{i}$ and $E_{i}$ $=(1 / 6)^{*} 1000$ for the $\mathrm{i}$-th model $(i=1,2, \ldots, 6)$. Finally, the test statistic is calculated, and the $p$-value is obtained. A small $p$-value $(<0.05)$ is a piece of evidence against the hypothesis that the six-candidate models are equally likely to be selected by the criterion. This indicates that the proportions of times the models attained minimum IC may not be equal. In other words, at least one model may be more likely to be selected by the criterion compared to other models when $p$-value $<0.05$. The overall test is conducted separately for each criterion to examine if certain model(s) consistently attain a higher chance to be selected by most criteria.

\subsubsection{Pairwise Test: Multiple Comparisons}

In case the overall proportion test shows evidence against equality of likelihoods of the six models, it is of interest to identify which model(s) may have a relatively higher chance of to be selected by an IC. This is done by multiple comparisons tests [74], which performs pairwise comparisons of all ${ }^{6} C_{2}=15$ pairs of proportions. For example, the hypothesis that model 1 and model 2 are equally likely to attain a minimum value of a given IC (i.e., equally likely to be selected) is denoted as follows.

$$
H_{0}: P_{1}=P_{2} \text { Vs. } H_{0}: P_{1} \neq P_{2}
$$

$H_{0}$ is rejected at $5 \%$ level of significance if the test statistic $Z=\frac{\hat{p}_{1}-\hat{p}_{2}}{\sqrt{\hat{p}(1-\hat{p})\left(\frac{1}{n_{1}}+\frac{1}{n_{2}}\right)}}$, where $\hat{p}=\frac{x_{1}+x_{2}}{n_{1}+n_{2}}$ results the $p$-value $<0.05$. By rejecting $H_{0}$, the pair-wise test suggests that one model may be more likely to be selected by a given IC than the other model. In such a case, the model that attains a higher $\hat{\pi}$ value can be declared to be the better model. Similarly, all other pairs of models are compared based on certain model selection criteria, and finally, a single or set of model(s) are identified that may be better than the other candidates. In this study, since we consider eight different criteria, the overall test and multiple comparisons are conducted separately for each criterion.

\section{Results and Discussion}

In this study, relevant adsorption pairs for all the IUPAC-classified adsorption isotherms are first selected for analysis. One adsorption pair data with more than one temperature consider for Type-I(b), Type-III, and Type-V. On the other hand, two different adsorption pairs with single temperature consider for Type-I(a), Type-II, Type-IV(a), Type-IV(b) and Type-VI IUPAC classified adsorption isotherm. Generalized reduced gradient (GRG) non-linear optimization methods have been employed to optimize the parameters of the model using two error evaluation functions RMSD and HYBRID for Type-I(a) and Type-I(b) adsorption isotherm. On the other hand, the only HYBRID error evaluation function is used for other types since Rahman et al. [21] showed that HYBRID error was better than 
other errors for the optimization of parameters. Bootstrap error mean, $\mathrm{CI}$, the value of model selection criteria, selection probabilities/rates of the model have been calculated, and two proportion tests have been performed for Type-I(a), Type-I(b), Type-III, and Type-V adsorption isotherms. For Type-II, Type-IV(a), Type-IV(b) and Type-VI, the bootstrap error means, CI, the value of model selection criteria have been presented.

\subsection{Type-I(a) Adsorption Isotherm}

Type-I(a) is recommended isotherm in the 2015 IUPAC report [14]. This type of isotherm is found for narrow microporous adsorbent having a pore size less than $1 \mathrm{~nm}$. For instance, adsorption of $\mathrm{N}_{2}$ onto K4-700 adsorbent at temperature 77 K [18] and Ar onto BIDC-X-700 adsorbent at temperature 87 K [19] showed Type-I(a) isotherm.

\subsubsection{Bootstrap Error Analysis and Model Selection Using Information Criteria}

$\mathrm{Hu}$ et al. [18] measured the adsorption isotherms at $77 \mathrm{~K}$ for adsorption of high-resolution $\mathrm{N}_{2}$ onto a K4-700. Cychosz et al. [19] measured adsorption isotherm at $87 \mathrm{~K}$ for adsorption of argon onto heteroatom-doped carbons BIDC-X-700 adsorbent. These isotherms are fitted with Tóth, D-A, Mod-BET, Ng et al., and Mahle model in the current study and presented in Figure 2.
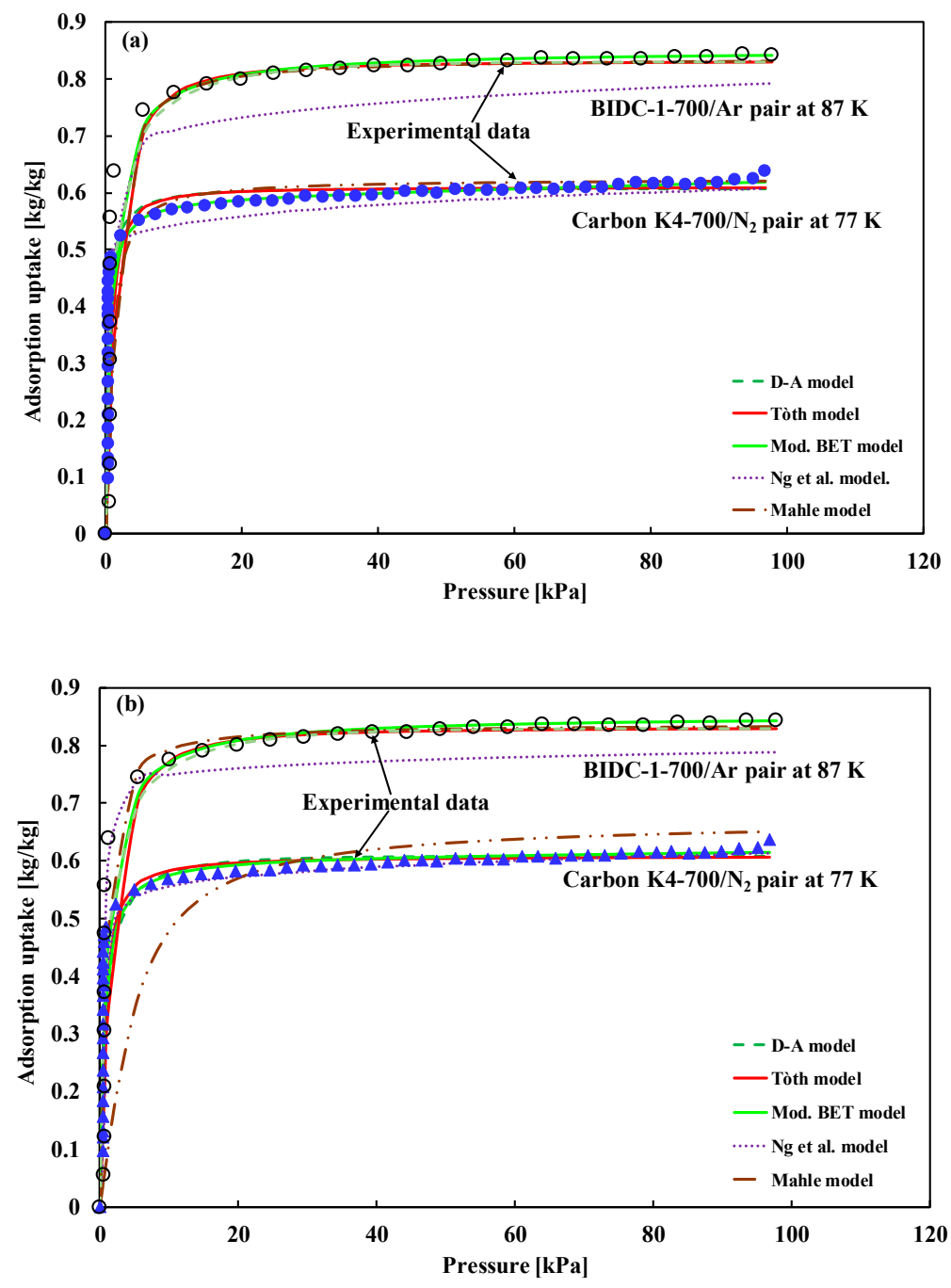

Figure 2. Type-I(a) adsorption isotherm of Carbon $\mathrm{K} 4-700 / \mathrm{N}_{2}$ and BIDC-1-700/Ar pairs (data are fitted with the D-A, Tóth, modified BET, Ng et al. and Mahle models using RMSD and HYBRID error evaluation functions) depicted in (a,b), respectively. 
Based on the bootstrap mean and CIs of the RMSD and HYBRID errors from Table 2, it is observed that the modified BET model has smaller average error and smaller CI than the other models.

Table 2. Mean error and confidence interval of error for $n=1000$ bootstrap samples for K4-700/ $\mathrm{N}_{2}$ and BIDC-1-700/Ar pairs.

\begin{tabular}{ccccc}
\hline Model & Mean RMSD & CI of RMSD & Mean HYBRID & CI of HYBRID \\
\hline K4-700/N 2 pair & & & \\
\hline Tóth & 0.0745 & $(0.045,0.0956)$ & 1.884 & $(1.24,2.152)$ \\
D-A & 0.0838 & $(0.047,0.0971)$ & 1.912 & $(1.55,2.923)$ \\
Mod. BET & 0.0638 & $(0.050,0.0723)$ & 1.871 & $(1.52,1.983)$ \\
Ng et al. & 0.1066 & $(0.032,0.3254)$ & 1.913 & $(1.43,3.851)$ \\
Mahle & 0.1019 & $(0.042,0.2321)$ & 4.146 & $(3.654,5.123)$ \\
\hline BIDC-1-700/Ar pair & & & & \\
\hline Tóth & 0.1047 & $(0.045,0.126)$ & 3.6648 & $(2.24,4.152)$ \\
D-A & 0.0936 & $(0.047,0.0971)$ & 8.9234 & $(6.55,10.923)$ \\
Mod. BET & 0.0872 & $(0.050,0.0986)$ & 3.5624 & $(2.52,4.783)$ \\
Ng et al. & 0.1245 & $(0.032,0.3254)$ & 12.354 & $(8.43,15.851)$ \\
Mahle & 0.1154 & $(0.042,0.2921)$ & 4.8132 & $(2.65,7.123)$ \\
\hline
\end{tabular}

The value of all information criteria in the bold number of modified BET model is small compared to other probable model for carbon K4-700/ $\mathrm{N}_{2}$ and BIDC-1-700/Ar adsorption pairs presented in Table 3, which means that considering all ICs and both error functions, modified BET models information loss is less compared to other models followed by the Tóth model. The probability of the possible models for Type-I(a) is graphically presented in Figure 3. It is marked that the selection rate/probability of the modified BET model is maximum among all the models considering all criteria for both adsorption pairs.

\subsubsection{Overall and Pairwise Proportion Tests}

The $p$-values of overall and pairwise tests for the equality of minimum information criteria for carbon $\mathrm{K} 4-700 / \mathrm{N}_{2}$ and BIDC-1-700/Ar pairs considering three more important models are expressed in Table 4. Here, the $p$-value of two tests are given, (i) equality of overall (all models) proportion test and (ii) equality of pairwise proportion test. For K4-700/ $\mathrm{N}_{2}$ pairs, Table 4 shows that $p$-value is very small, which is close to zero and less than 0.01 . Thus, it indicates that the overall and pairwise proportion tests are highly statistically significant at $1 \%$ level of significance. It states that the Mod. BET model has significantly less information loss compare to other probable models. For BIDC-1-700/Ar pairs, Table 4 shows that $p$-value is very small, which is close to zero and less than 0.01 except pairwise test between modified BET and Tóth model. Thus, it indicates that the overall and pairwise (Mod. BET vs. D-A) proportion tests are statistically significant at $1 \%$ level of significance, but modified BET and Tóth is insignificant. It states that the Mod. BET and Tóth model are equally important for Type-I(a).

\subsection{Type-I(b) Adsorption Isotherm}

The Type-I(b) IUPAC $[15,16]$ classified adsorption isotherm is mainly characterized by monolayer adsorption. The uptake continuously increases with pressure and reaches a plateau at saturation pressure. The maximum absorption is determined by the available micropore volume. 
Table 3. Optimal isotherm employing model selection criteria for $n=1000$ bootstrap samples for $\mathrm{K} 4-700 / \mathrm{N}_{2}$ and BIDC-1-700/Ar pair.

\begin{tabular}{|c|c|c|c|c|c|c|c|c|}
\hline Model & $\begin{array}{l}\text { Error } \\
\text { Mean }\end{array}$ & $A I C$ & $B I C$ & $A I C_{c}$ & $m A I C$ & AIC3 & CAIC & $A B I C$ \\
\hline \multicolumn{9}{|c|}{$\mathrm{K} 4-700 / \mathrm{N}_{2}$ pair } \\
\hline \multicolumn{9}{|c|}{ Using RMSD error mean } \\
\hline Tóth & 0.0745 & -223.16 & -214.78 & -222.43 & -199.16 & -219.16 & -210.78 & -227.36 \\
\hline $\mathrm{D}-\mathrm{A}$ & 0.0838 & -218.08 & -211.79 & -217.65 & -206.08 & -215.08 & -208.79 & -221.23 \\
\hline Mod. BET & 0.0638 & -234.48 & -228.20 & -234.06 & -222.48 & -231.48 & -225.20 & -237.64 \\
\hline $\mathrm{Ng}$ et al. & 0.1066 & -195.68 & -181.02 & -193.53 & -111.68 & -188.68 & -174.02 & -203.04 \\
\hline Mahle & 0.1019 & -204.38 & -196.00 & -203.65 & -180.38 & -200.38 & -192.00 & -208.58 \\
\hline \multicolumn{9}{|c|}{ Using HYBRID error mean } \\
\hline Tóth & 1.884 & -29.33 & -20.96 & -28.61 & -5.33 & -25.33 & -16.96 & -33.54 \\
\hline D-A & 1.912 & -30.47 & -24.19 & -30.05 & -18.47 & -27.47 & -21.19 & -33.63 \\
\hline Mod. BET & 1.871 & -31.78 & -25.49 & -31.35 & -19.78 & -28.78 & -22.49 & -34.93 \\
\hline Ng et al. & 1.913 & -22.44 & -7.78 & -20.29 & 61.56 & -15.44 & -0.78 & -29.80 \\
\hline Mahle & 4.146 & 17.96 & 26.34 & 18.69 & 41.96 & 21.96 & 30.34 & 13.76 \\
\hline \multicolumn{9}{|c|}{ BIDC-1-700/Ar pair } \\
\hline \multicolumn{9}{|c|}{ Using RMSD error mean } \\
\hline Tóth & 0.1047 & -69.02 & -63.69 & -67.28 & -45.02 & -65.02 & -59.69 & -76.12 \\
\hline $\mathrm{D}-\mathrm{A}$ & 0.0936 & -74.15 & -70.16 & -73.15 & -62.15 & -71.15 & -67.16 & -79.48 \\
\hline Mod. BET & 0.0872 & -76.14 & -72.14 & -75.14 & -64.14 & -73.14 & -69.14 & -81.47 \\
\hline Ng et al. & 0.1245 & -58.17 & -48.84 & -52.57 & 25.83 & -51.17 & -41.84 & -70.60 \\
\hline Mahle & 0.1154 & -66.29 & -60.96 & -64.55 & -42.29 & -62.29 & -56.96 & -73.40 \\
\hline \multicolumn{9}{|c|}{ Using HYBRID error mean } \\
\hline Tóth & 3.6648 & 30.54 & 35.86 & 32.27 & 54.54 & 34.54 & 39.86 & 23.43 \\
\hline $\mathrm{D}-\mathrm{A}$ & 8.9234 & 53.45 & 57.45 & 54.45 & 65.45 & 56.45 & 60.45 & 48.12 \\
\hline Mod. BET & 3.5624 & 27.74 & 31.74 & 28.74 & 39.74 & 30.74 & 34.74 & 22.41 \\
\hline Ng et al. & 12.354 & 70.56 & 79.89 & 76.16 & 154.56 & 77.56 & 86.89 & 58.12 \\
\hline Mahle & 4.8132 & 38.17 & 43.50 & 39.91 & 62.17 & 42.17 & 47.50 & 31.06 \\
\hline
\end{tabular}

* The shaded cells indicate lowest value for a particular information criterion.

Table 4. $p$-value of the overall and pairwise test of equality of the values of minimum information criteria (Values outside and inside of parentheses represent HYBRID and RMSD errors, respectively) for carbon $\mathrm{K} 4-700 / \mathrm{N}_{2}$ and BIDC-1-700/Ar pairs.

\begin{tabular}{|c|c|c|c|c|c|c|c|}
\hline Test & $A I C$ & $B I C$ & $A I C_{c}$ & $m A I C$ & AIC3 & CAIC & $A B I C$ \\
\hline \multicolumn{8}{|c|}{ Carbon $\mathrm{K} 4-700 / \mathrm{N}_{2}$} \\
\hline Overall & $\begin{array}{c}2.0 \times 10^{-15} \\
\left(2.3 \times 10^{-14}\right)\end{array}$ & $\begin{array}{l}2.1 \times 10^{-}(2.1 \\
\left.\quad \times 10^{-13}\right)\end{array}$ & $\begin{array}{c}2.2 \times 10^{-15} \\
\left(2.0 \times 10^{-14}\right)\end{array}$ & $\begin{array}{c}2.0 \times 10^{-13} \\
\left(2.2 \times 10^{-12}\right)\end{array}$ & $\begin{array}{c}2.1 \times 10^{-15} \\
\left(2.2 \times 10^{-13}\right)\end{array}$ & $\begin{array}{c}2.0 \times 10^{-14} \\
\left(2.2 \times 10^{-14}\right)\end{array}$ & $\begin{array}{c}2.1 \times 10^{-15} \\
\left(2.2 \times 10^{-13}\right)\end{array}$ \\
\hline $\begin{array}{l}\text { Mod. BET } \\
\text { vs. Tóth }\end{array}$ & $\begin{array}{c}2.0 \times 10^{-4} \\
\left(2.1 \times 10^{-5}\right)\end{array}$ & $\begin{array}{c}2.1 \times 10^{-5} \\
\left(2.0 \times 10^{-4}\right)\end{array}$ & $\begin{array}{c}2.2 \times 10^{-3} \\
\left(2.1 \times 10^{-4}\right)\end{array}$ & $\begin{array}{c}1.4 \times 10^{-} \\
\left(1.2 \times 10^{-3}\right)\end{array}$ & $\begin{array}{c}1.8 \times 10^{-4} \\
\left(2.1 \times 10^{-3}\right)\end{array}$ & $\begin{array}{c}1.9 \times 10^{-3} \\
\left(2.1 \times 10^{-3}\right)\end{array}$ & $\begin{array}{c}2.1 \times 10^{-4} \\
\left(2.2 \times 10^{-3}\right)\end{array}$ \\
\hline $\begin{array}{c}\text { Mod. BET } \\
\text { vs. D-A }\end{array}$ & $\begin{array}{c}1.5 \times 10^{-8}(1.9 \\
\left.\times 10^{-8}\right)\end{array}$ & $\begin{array}{c}2.1 \times 10^{-9} \\
\left(2.0 \times 10^{-7}\right)\end{array}$ & $\begin{array}{c}1.1 \times 10^{-8} \\
\left(2.1 \times 10^{-8}\right)\end{array}$ & $\begin{array}{c}2.0 \times 10^{-7} \\
\left(2.0 \times 10^{-7}\right)\end{array}$ & $\begin{array}{c}2.0 \times 10^{-8} \\
\left(1.9 \times 10^{-7}\right)\end{array}$ & $\begin{array}{c}1.7 \times 10^{-9} \\
\left(2.2 \times 10^{-9}\right)\end{array}$ & $\begin{array}{c}2.1 \times 10^{-11} \\
\left(1.9 \times 10^{-12}\right)\end{array}$ \\
\hline \multicolumn{8}{|c|}{ BIDC-1-700/Ar pair } \\
\hline Overall & $\begin{array}{c}2.0 \times 10^{-4} \\
\left(2.3 \times 10^{-3}\right)\end{array}$ & $\begin{array}{c}2.2 \times 10^{-3} \\
\left(2.1 \times 10^{-3}\right)\end{array}$ & $\begin{array}{c}2.1 \times 10^{-4} \\
\left(2.3 \times 10^{-3}\right)\end{array}$ & $\begin{array}{c}2.4 \times 10^{-3} \\
\left(2.1 \times 10^{-4}\right)\end{array}$ & $\begin{array}{c}2.1 \times 10^{-4} \\
\left(2.3 \times 10^{-5}\right)\end{array}$ & $\begin{array}{c}2.5 \times 10^{-3} \\
\left(2.1 \times 10^{-4}\right)\end{array}$ & $\begin{array}{c}2.2 \times 10^{-4} \\
\left(2.3 \times 10^{-3}\right)\end{array}$ \\
\hline $\begin{array}{l}\text { Mod. BET } \\
\text { vs. Tóth }\end{array}$ & $0.0235(0.0351)$ & $0.0351(0.0421)$ & $0.2363(0.5324)$ & $0.0425(0.0354)$ & $0.0573(0.0784)$ & $0.2381(0.1465)$ & $0.0715(0.0471)$ \\
\hline $\begin{array}{l}\text { Mod. BET } \\
\text { vs. D-A }\end{array}$ & $\begin{array}{c}1.6 \times 10^{-3} \\
\left(1.7 \times 10^{-4}\right)\end{array}$ & $\begin{array}{c}1.1 \times 10^{-4} \\
\left(2.4 \times 10^{-3}\right)\end{array}$ & $\begin{array}{c}1.5 \times 10^{-3} \\
\left(2.3 \times 10^{-3}\right)\end{array}$ & $\begin{array}{c}1.4 \times 10^{-4} \\
\left(2.2 \times 10^{-3}\right)\end{array}$ & $\begin{array}{c}2.2 \times 10^{-3} \\
\left(1.5 \times 10^{-4}\right)\end{array}$ & $\begin{array}{c}1.9 \times 10^{-4} \\
\left(2.1 \times 10^{-3}\right)\end{array}$ & $\begin{array}{l}2.2 \times 10^{-3} \\
(1.44)\end{array}$ \\
\hline
\end{tabular}



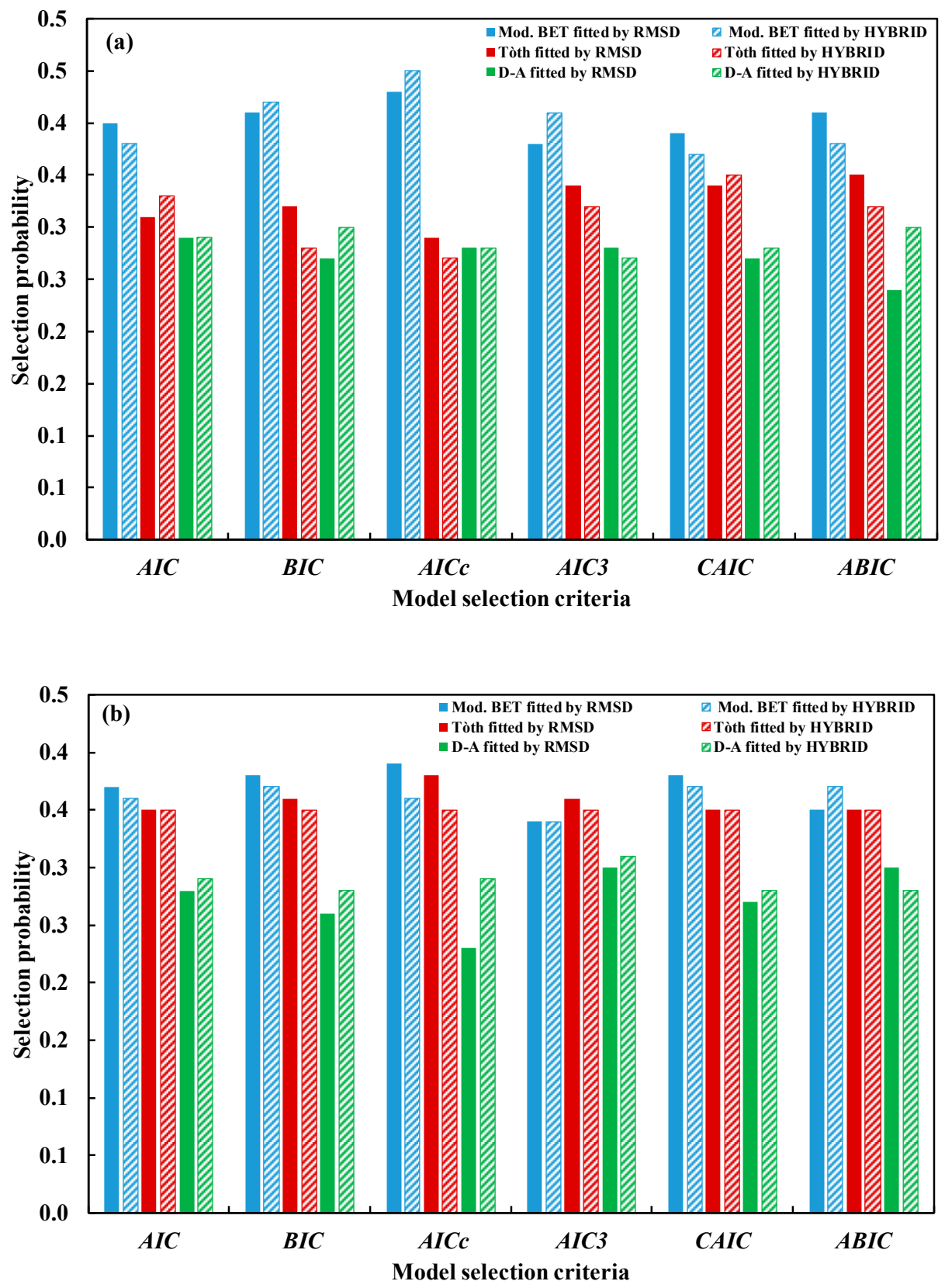

Figure 3. Probability/rate of selecting models for K4-700/ $\mathrm{N}_{2}$ and BDIC-1-700/Ar of Type-I(a) adsorption isotherms using both RMSD and HYBRID errors depicted in $(\mathbf{a}, \mathbf{b})$, respectively.

\subsubsection{Bootstrap Error Analysis and Model Selection Using Information Criteria}

Pal et al. [22] assessed the adsorption isotherms for adsorption of carbon-based composites onto carbon dioxide gas. They considered temperatures $30^{\circ} \mathrm{C}, 50{ }^{\circ} \mathrm{C}$ and $70{ }^{\circ} \mathrm{C}$. The isotherms are fitted with Tóth and modified D-A, Langmuir, Freundlich, D-A, and Hill model in the current study and presented in Figure 4. Applying bootstrap error analysis, for each type of isotherm, RMSD, HYBRID error mean, and CI of errors are measured. The results are presented in Table 5. It shows the mean RMSD and HYBRID errors as well as $95 \%$ confidence interval of the two, corresponding to all the isotherm models. It is observed that the Tóth model provides the minimum error and minimum 95\% CI of the bootstrap sample compared to the other models. 

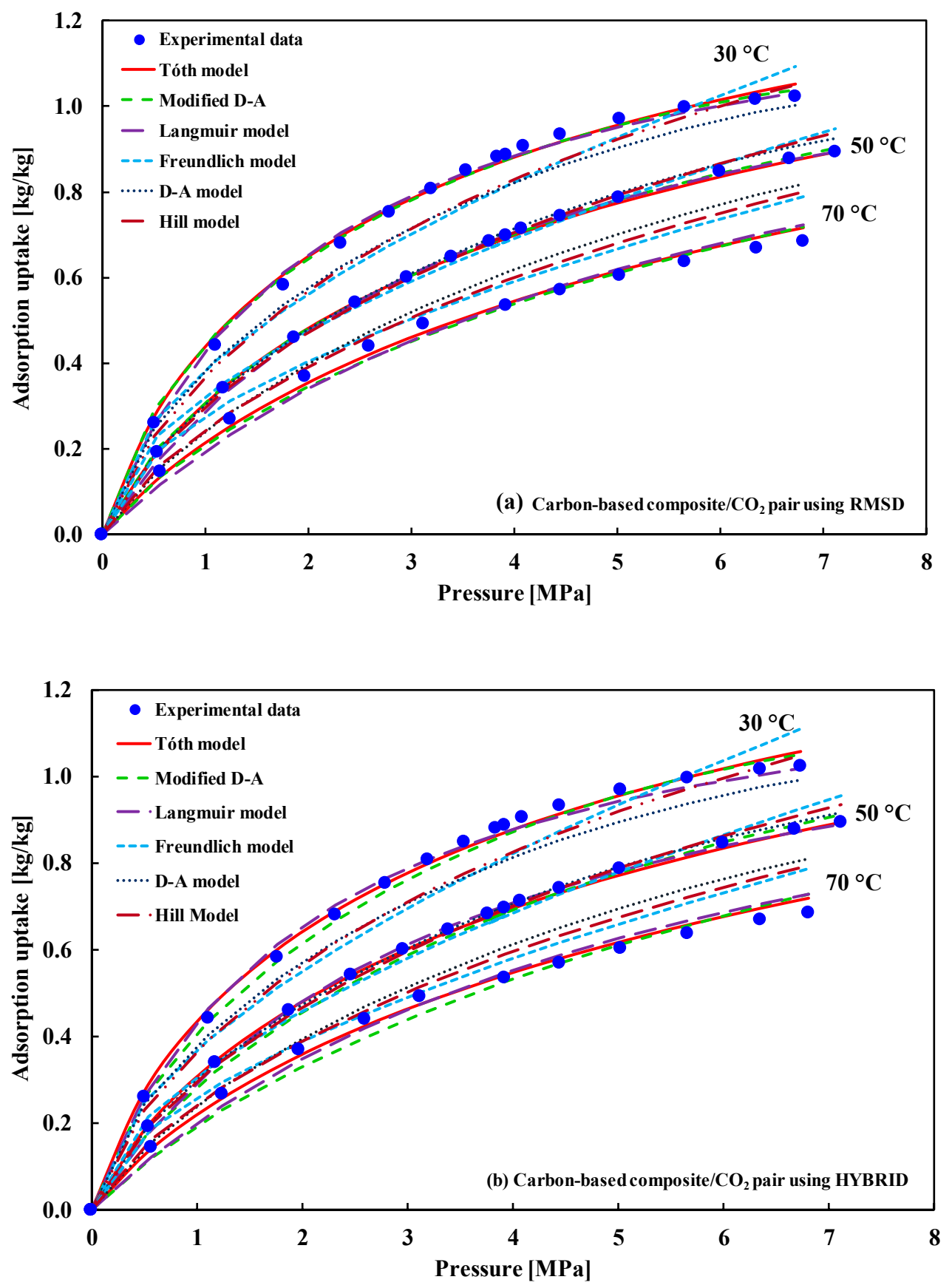

Figure 4. Type-I(b) adsorption isotherm of carbon-based composite/ $\mathrm{CO}_{2}$ pair (data are fitted with the Tóth, modified D-A, Langmuir, Freundlich, and Hill models using RMSD and HYBRID error evaluation function, depicted in (a,b), respectively).

Table 5. Mean error and confidence interval of error for $n=1000$ bootstrap samples.

\begin{tabular}{ccccc}
\hline Model & Mean RMSD & CI of RMSD & Mean HYBRID & CI of HYBRID \\
\hline D-A & 0.05624 & $(0.0457,0.0650)$ & 0.4893 & $(0.3432,0.6382)$ \\
Mod. D-A & 0.01532 & $(0.0125,0.0179)$ & 0.1096 & $(0.0745,0.1438)$ \\
Tóth & 0.01435 & $(0.0122,0.0165)$ & 0.0373 & $(0.0276,0.0473)$ \\
Freundlich & 0.05178 & $(0.0451,0.0583)$ & 0.4353 & $(0.3282,0.5444)$ \\
Langmuir & 0.01839 & $(0.0157,0.0209)$ & 0.0724 & $(0.0516,0.0960)$ \\
Hill & 0.04871 & $(0.0451,0.0583)$ & 0.3816 & $(0.2740,0.4965)$ \\
\hline
\end{tabular}


From Table 6, it is observed that for the composite/ $\mathrm{CO}_{2}$ adsorption pair, the values of all information criteria for Tóth model are small compared to other probable models, considering HYBRID error mean; this implies that considering all IC, the Tóth model's information loss is less when compared to other models. The results are similar in the case of RMSD error mean; i.e., the values of all information criteria that correspond to the Tóth model are small compared to other probable models, except with the case of mAIC, which attains the minimum value in Langmuir model. Thus the analysis shows that, for this type of isotherm, the Tóth model's information loss is less compared to other models. The probability of the possible model for Type-I(b) is graphically presented in Figure 5. This bar diagram shows the selection probability of the models for each of the model selection criteria. It is evident that the selection rate/probability of the Tóth model is highest among all the models considering all criteria. According to $A I C$, using the RMSD error function, the selection probability of Tóth model is approximately $70 \%$. On the other hand, if we use the HYBRID error function, the selection probability of the Tóth model is about $80 \%$.

Table 6. Optimal isotherm employing model selection criteria for $n=1000$ bootstrap samples.

\begin{tabular}{ccccccccc}
\hline Model & $\begin{array}{c}\text { Error } \\
\text { Mean }\end{array}$ & AIC & BIC & AIC & mAIC & AIC3 & CAIC & ABIC \\
\hline \multicolumn{7}{c}{ Using HYBRID error mean } \\
\hline D-A & 0.4893 & -56.61 & -51.70 & -55.90 & -44.61 & -53.61 & -48.70 & -61.08 \\
Mod. D-A & 0.1096 & -114.43 & -107.88 & -113.22 & -90.43 & -110.43 & -103.88 & -120.38 \\
Tóth & 0.0373 & -157.53 & -150.98 & -156.32 & -133.53 & -153.53 & -146.98 & -163.49 \\
Freundlich & 0.4353 & -63.29 & -60.01 & -62.95 & -59.29 & -61.29 & -58.01 & -66.27 \\
Langmuir & 0.0724 & -133.03 & -128.11 & -132.32 & -121.03 & -130.03 & -125.11 & -137.50 \\
Hill & 0.3815 & -66.56 & -61.65 & -65.85 & -54.56 & -63.56 & -58.65 & -71.03 \\
\hline & & & Using RMSD error mean & & & \\
\hline D-A & 0.0562 & -143.15 & -138.24 & -142.44 & -131.15 & -140.15 & -135.24 & -147.62 \\
Mod. D-A & 0.0153 & -193.17 & -186.62 & -191.96 & -169.17 & -189.17 & -182.62 & -199.12 \\
Tóth & 0.0143 & -195.78 & -189.23 & -194.57 & -171.78 & -191.78 & -185.23 & -201.74 \\
Freundlich & 0.0517 & -148.45 & -145.18 & -148.11 & -144.45 & -146.45 & -143.18 & -151.43 \\
Langmuir & 0.0183 & -187.86 & -182.95 & -187.16 & -175.86 & -184.86 & -179.95 & -192.33 \\
Hill & 0.0487 & -148.90 & -143.99 & -148.19 & -136.90 & -145.90 & -140.99 & -153.37 \\
\hline
\end{tabular}

* The shaded cells indicate lowest value for a particular information criterion.

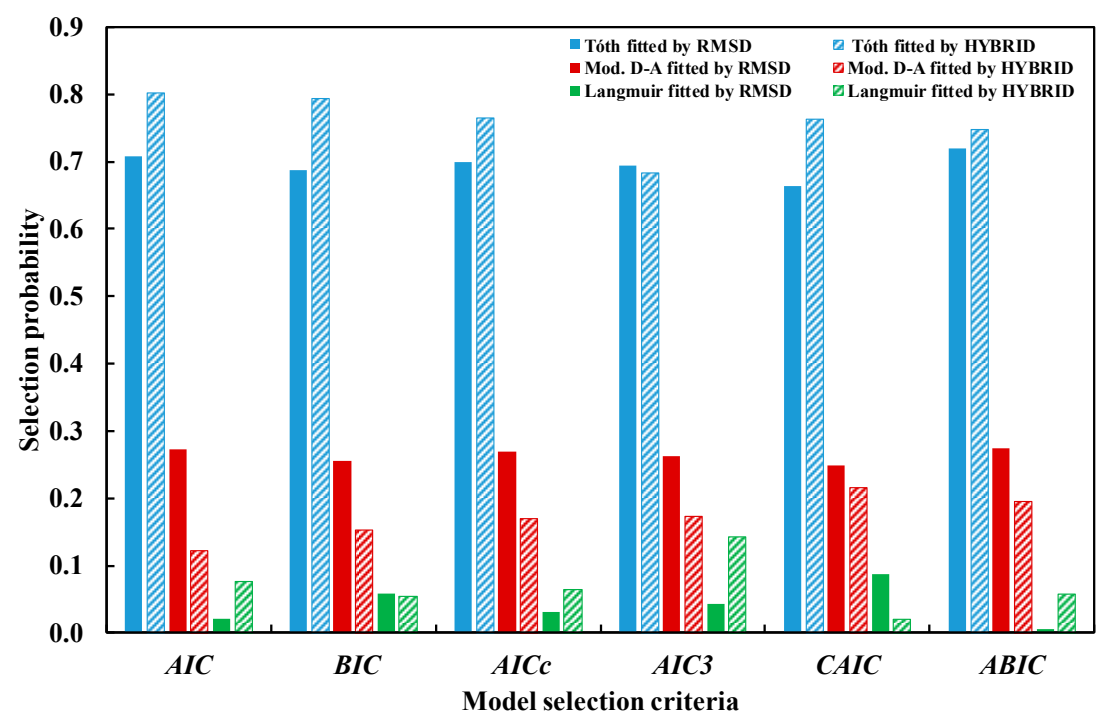

Figure 5. Probability/rate of selecting models for Type-I(b) adsorption isotherms using both RMSD and HYBRID errors. 


\subsubsection{Overall and Pairwise Proportion Tests}

$p$-value of overall and pairwise test for the equality of minimum information criteria considering Tóth, modified D-A, and Langmuir models are expressed in Table 7. Here, the $p$-value of two tests are given, (i) equality of overall (all models) proportion test and (ii) equality of pairwise proportion test. The above table shows that $p$-value is very small, which is close to zero and less than 0.01 . Thus, it indicates that the overall and pairwise proportion tests are highly statistically significant at $1 \%$ level of significance. It states that the Tóth model has significantly less information loss compared to other probable models.

Table 7. $p$-value of the overall and pairwise test of equality of the values of minimum information criteria (values outside and inside of parentheses represent HYBRID and RMSD errors, respectively).

\begin{tabular}{cccccccc}
\hline Test & AIC & BIC & AIC & mAIC & AIC3 & CAIC \\
\hline Overall & $2.1 \times 10^{-16}$ & $2.1 \times 10^{-15}$ & $2.1 \times 10^{-16}$ & $2.2 \times 10^{-14}$ & $2.2 \times 10^{-16}$ & $2.0 \times 10^{-13}$ & $2.2 \times 10^{-16}$ \\
& $\left(2.2 \times 10^{-12}\right)$ & $\left(2.2 \times 10^{-13}\right)$ & $\left(2.2 \times 10^{-14}\right)$ & $\left(2.2 \times 10^{-13}\right)$ & $\left(2.2 \times 10^{-14}\right)$ & $\left(2.2 \times 10^{-16}\right)$ & $\left(2.2 \times 10^{-15}\right)$ \\
Tóth vs. & $2.0 \times 10^{-12}$ & $2.0 \times 10^{-11}$ & $2.0 \times 10^{-11}$ & $1.0 \times 10^{-10}$ & $2.0 \times 10^{-13}$ & $2.1 \times 10^{-12}$ & $2.0 \times 10^{-13}$ \\
Mod. D-A & $\left(2.0 \times 10^{-16}\right)$ & $\left(2.0 \times 10^{-16}\right)$ & $\left(2.0 \times 10^{-16}\right)$ & $\left(1.0 \times 10^{-10}\right)$ & $\left(2.0 \times 10^{-16}\right)$ & $\left(2.0 \times 10^{-16}\right)$ & $\left(2.0 \times 10^{-16}\right)$ \\
Mod.D-A & $1.9 \times 10^{-15}$ & $2.0 \times 10^{-16}$ & $2.1 \times 10^{-15}$ & $2.0 \times 10^{-16}$ & $2.0 \times 10^{-16}$ & $2.0 \times 10^{-16}$ & $2.0 \times 10^{-16}$ \\
vs. & $\left(2.0 \times 10^{-16}\right)$ & $\left(2.0 \times 10^{-16}\right)$ & $\left(2.0 \times 10^{-16}\right)$ & $\left(2.0 \times 10^{-16}\right)$ & $\left(2.0 \times 10^{-16}\right)$ & $\left(2.0 \times 10^{-16}\right)$ & $\left(2.0 \times 10^{-16}\right)$ \\
Langmuir & & & & & & \\
\hline
\end{tabular}

\subsection{Type-II Adsorption Isotherm}

The Type-II isotherm is characterized by multilayer adsorption [15] and nearly analogous to the Type-I(b) shape; the only difference between the two is the absence of the plateau in Type-II, which is observed in Type-I(b) isotherms. The uptake continuously increases even when the pressure ratio is close to unity. This type of behavior is found for microporous adsorbents. Two isotherm data, for Type-II, are analyzed in the current study, they are isotherms of (i) water adsorption onto alumina at $22{ }^{\circ} \mathrm{C}$ and (ii) water onto poorly crystalline boehmite at $20^{\circ} \mathrm{C}$. A previous study [21] on analysis of the sum of normalized error (SNE) showed that the HYBRID error function is appropriate to use for parameter optimization for almost all isotherm models. That is why the HYBRID error is used in the current study for the analysis of all types of onwards.

Naono et al. [31] determined the adsorption isotherms for adsorption of water onto alumina at $20^{\circ} \mathrm{C}$. Wang et al. [32] use water adsorption onto poorly crystalline boehmite at $22{ }^{\circ} \mathrm{C}$. Both of these adsorption isotherms exhibit Type-II characteristics and are considered in the current study. The isotherm first fitted with modified BET, Ng et al., D-A, Tóth, Langmuir, and Redlich-Peterson models, and the fitted isotherms are represented in Figure 6. Bootstrap error analysis is performed, and the results of bootstrap error mean, and $95 \% \mathrm{CI}$ are presented in Table 8.

Table 8. Mean error and confidence interval of HYBRID error for $n=1000$ bootstrap samples.

\begin{tabular}{cccccc}
\hline \multicolumn{3}{c}{ Alumina/Water Pair } & \multicolumn{3}{c}{ Boehmite/Water Pair } \\
\hline Model & Mean Error & $\mathbf{9 5 \%}$ CI of Error & Model & Mean Error & 95\% CI of Error \\
\hline Mod. BET & 0.2739 & $(0.1476,0.4204)$ & Mod. BET & 0.0079 & $(0.0028,0.0141)$ \\
Ng et al. & 0.8420 & $(0.3389,1.5064)$ & Ng et al. & 0.0311 & $(0.0121,0.0588)$ \\
D-A & 1.0182 & $0.1739,2.5075)$ & D-A & 0.0357 & $(0.0132,0.0743)$ \\
Tóth & 1.9345 & $(1.2436,2.6768)$ & Tóth & 0.6532 & $(0.2401,1.2636)$ \\
Redlich-Peterson & 1.6072 & $(0.9935,2.3879)$ & Langmuir & 1.4360 & $(0.5127,2.7516)$ \\
\hline
\end{tabular}



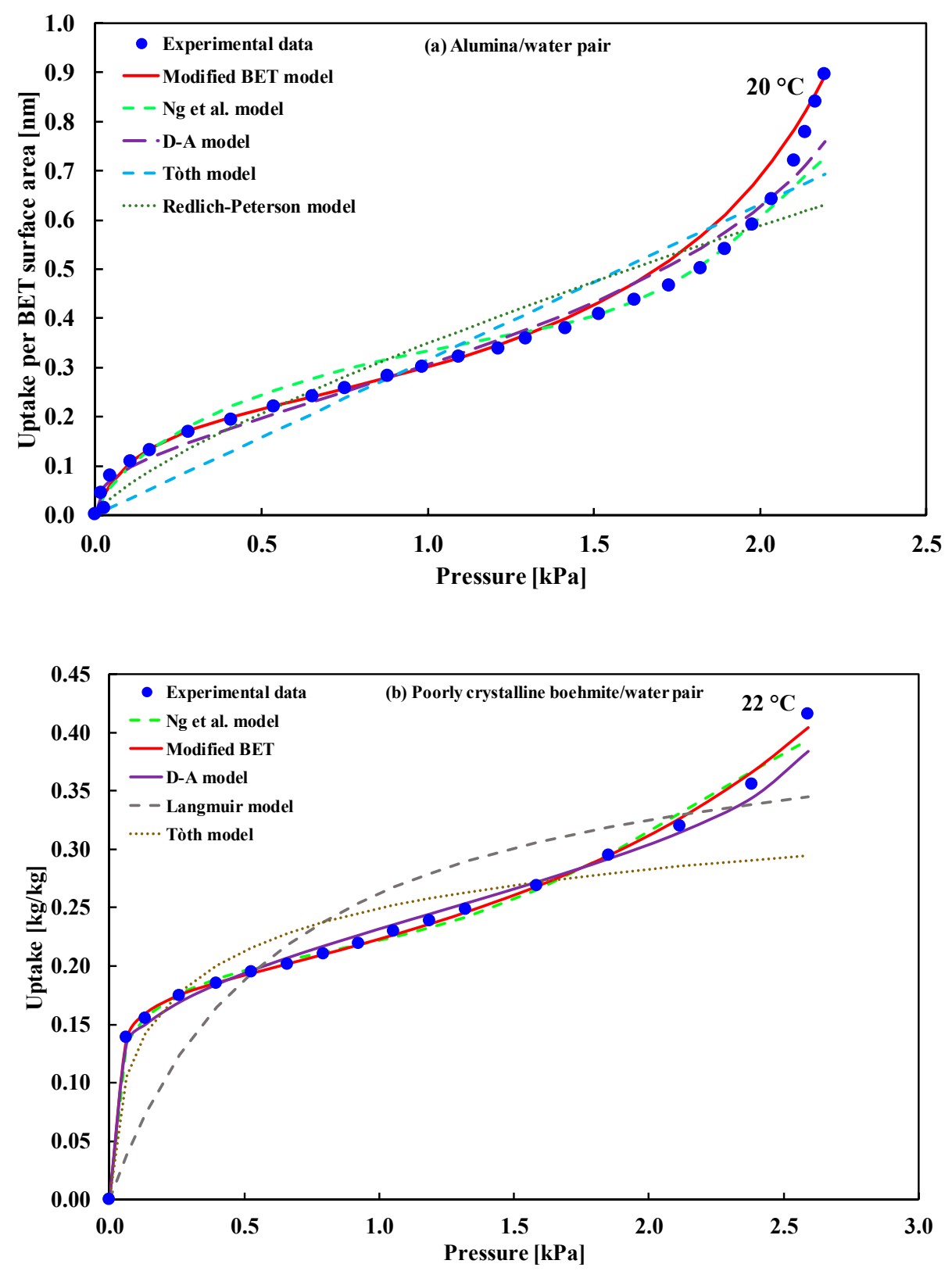

Figure 6. Type-II adsorption isotherms; (a) alumina/water pair and (b) poorly crystalline boehmite/water pair. Data are fitted with the modified BET, Ng et al., D-A, Tòth, Langmuir, and Redlich-Peterson models using the HYBRID error evaluation function.

Based on the bootstrap mean and CIs of the HYBRID errors, we observe that on average, the modified BET model has smaller errors and a minimum $95 \%$ confidence interval of bootstrap sample than the other models. The ICs of all the models is also determined in the current study and presented in Table 9. It is observed that all the information criteria corresponding to the modified BET model are smaller than the same corresponding to other isotherm models, and this statement is valid for both the adsorbate/adsorbent pairs. This signifies that the information loss in the case of the modified BET model is less than that corresponding to other isotherm models. 
Table 9. Optimal isotherm employing model selection criteria using HYBRID error mean of $n=1000$ bootstrap samples.

\begin{tabular}{ccccccccc}
\hline \multirow{2}{*}{ Model } & $\begin{array}{c}\text { Mean } \\
\text { Error }\end{array}$ & AIC & BIC & AIC & mAIC & AIC3 & CAIC & ABIC \\
\hline \multicolumn{8}{c}{ Adsorption of water onto alumina } \\
\hline Mod. BET & 0.2739 & -41.32 & -37.44 & -40.28 & -29.32 & -38.32 & -34.44 & -46.76 \\
Ng et al. & 0.8420 & -3.00 & 6.07 & 2.89 & 81.00 & 4.00 & 13.07 & -15.68 \\
D-A & 1.0182 & -5.87 & -1.98 & -4.82 & 6.13 & -2.87 & 1.02 & -11.30 \\
Tóth & 1.9345 & 13.46 & 18.65 & 15.28 & 37.46 & 17.46 & 22.65 & 6.22 \\
Redlich-Peterson & 1.6072 & 8.46 & 13.64 & 10.28 & 32.46 & 12.46 & 17.64 & 1.21 \\
\hline \multicolumn{8}{c}{ Adsorption of water onto poorly crystalline boehmite } \\
\hline Mod. BET & 0.0079 & -70.43 & -68.11 & -68.43 & -58.43 & -67.43 & -65.11 & -77.30 \\
Ng et al. & 0.0311 & -40.48 & -35.07 & -26.48 & 43.52 & -33.48 & -28.07 & -56.50 \\
D-A & 0.0356 & -46.31 & -44.00 & -44.31 & -34.31 & -43.31 & -41.00 & -53.18 \\
Tóth & 0.6532 & 2.24 & 5.33 & 5.87 & 26.24 & 6.24 & 9.33 & -6.91 \\
Langmuir & 1.4359 & 12.84 & 15.16 & 14.84 & 24.84 & 15.84 & 18.16 & 5.98 \\
\hline
\end{tabular}

${ }^{*}$ The shaded cells indicate lowest value for a particular information criterion.

\subsection{Type-III Adsorption Isotherm}

The shape of the Type-III adsorption isotherm is convex $[15,16]$. At low pressures, the uptake is low, but it increases sharply at the high pressures. Maroulis et al. [33] fitted the GAB model for the adsorption of moisture on the dried fruits. They considered temperatures of $15^{\circ} \mathrm{C}, 30^{\circ} \mathrm{C}, 45^{\circ} \mathrm{C}$ and $60^{\circ} \mathrm{C}$. In the current study, these isotherms are fitted with GAB, modified BET, $\mathrm{Ng}$ et al., modified Langmuir, Sun and Chakraborty, and D-A models and the results are shown in Figure 7. To investigate the model selection bootstrap error mean, $95 \%$ CI of $n=1000$ bootstrap sample and model selection criteria are determined and presented in Table 10. It is evident that considering all information criteria, the GAB model's information loss is less compared to all other models. Mean error and 95\% confidence interval of bootstrap samples are also small when the GAB model is considered in the fitting.

Figure 8 shows the selection probability of three models for each criterion. The bar diagram indicates that the selection rate/probability of the GAB model for adsorption of moisture/dried raisin pair is more than $80 \%$, whereas the modified BET model has a selection probability of $10 \%$ approximately for most of the information criteria except BIC and mAIC.

Table 10. Optimal isotherm employing model selection criteria using HYBRID error mean of $n=1000$ bootstrap samples.

\begin{tabular}{cccccccccc}
\hline Model & $\begin{array}{c}\text { Mean } \\
\text { Error }\end{array}$ & $\begin{array}{c}\text { 95\% CI } \\
\text { of Error }\end{array}$ & AIC & BIC & AIC & mAIC & AIC3 & CAIC & ABIC \\
\hline GAB model & 0.2932 & $\begin{array}{l}(0.1720, \\
0.4280)\end{array}$ & -73.10 & -64.66 & -71.34 & -33.10 & -68.10 & -59.66 & -80.30 \\
Mod. BET & 0.8758 & $\begin{array}{l}(0.3509, \\
1.5002)\end{array}$ & -33.33 & -28.26 & -32.66 & -21.33 & -30.33 & -25.26 & -37.65 \\
Ng et al. & 1.0613 & $\begin{array}{l}(0.6907, \\
1.4828)\end{array}$ & -17.64 & -5.82 & -14.14 & 66.36 & -10.64 & 1.18 & -27.73 \\
D-A & 1.2565 & $\begin{array}{l}(0.6192, \\
2.0008)\end{array}$ & -18.89 & -13.82 & -18.22 & -6.89 & -15.89 & -10.82 & -23.21 \\
Sun and & 1.3858 & $\begin{array}{l}(0.7615, \\
2.0736)\end{array}$ & -12.97 & -6.22 & -11.83 & 11.03 & -8.97 & -2.22 & -18.73 \\
Chakraborty & & & & & & & & & \\
Mod. Langmuir & 0.7541 & $1.2238)$ & -31.31 & -19.49 & -27.81 & 52.69 & -24.31 & -12.49 & -41.39 \\
\hline
\end{tabular}

* The shaded cells indicate lowest value for a particular information criterion. 


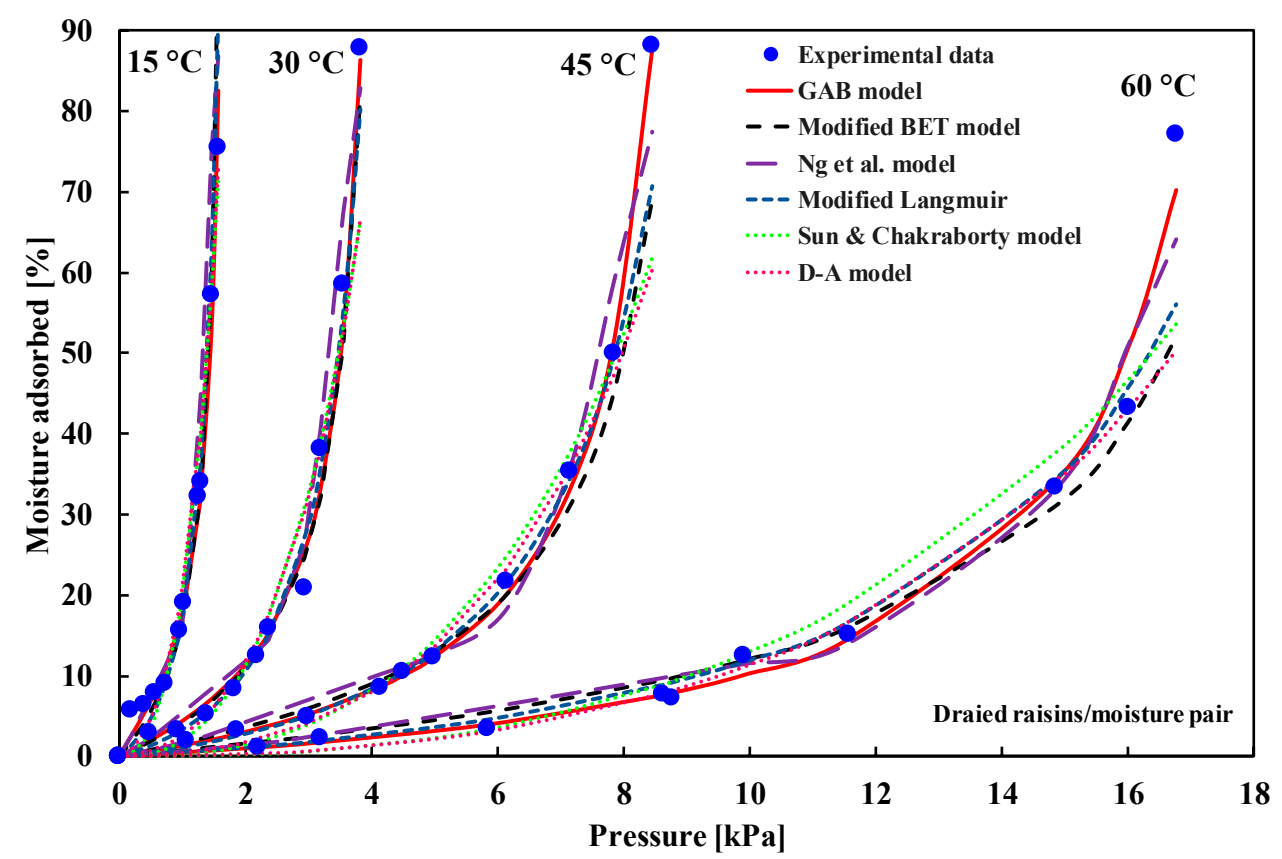

Figure 7. Type-III adsorption isotherms for dried raisins/moisture pair; experimental data are fitted with the GAB, modified BET, Ng et al., modified Langmuir, Sun and Chakraborty and D-A models using HYBRID error evaluation function.

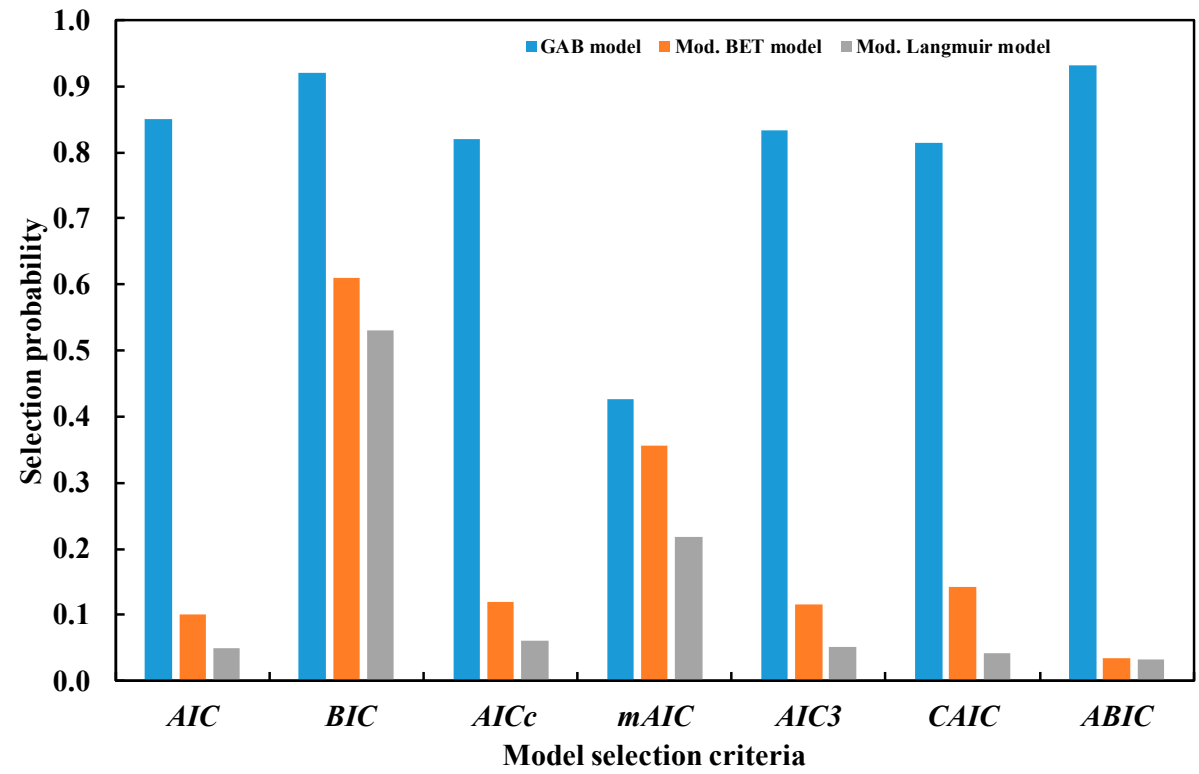

Figure 8. Probability of selecting models of Type-III adsorption isotherms for different information criteria using HYBRID errors.

The overall and pairwise proportion tests are also conducted, and the results are presented in Table 11. It is observed that the $p$-value is very small and much less than 0.01 . This result indicates that the overall and pairwise proportion tests are highly statistically significant. It also reconfirms that the GAB model has significantly less information loss compared to other models taken into consideration.

\subsection{Type-IV(a) Adsorption Isotherm}

The Type-IV(a) IUPAC classified adsorption isotherm is described by multilayer adsorption, which is a combination of Type-I(b) and Type-II isotherms. This type is characterized by its hysteresis loop, 
caused by the filling of mesopores. In the present investigation, two isotherms data are considered; (i) water adsorption onto polyvinylidene chloride (PVDC- $600{ }^{\circ} \mathrm{C}$ ) at $35^{\circ} \mathrm{C}$ and (ii) water onto tripolis (dispersed silica) at $21^{\circ} \mathrm{C}$. Do et al. [34] presented a model that can describe the behavior of water adsorption onto highly oxidized carbon at $35^{\circ} \mathrm{C}$. Rakitskaya et al. [35] fitted the BET model to describe the adsorption of water onto tripolis. In the current study, these isotherms are fitted with the $\mathrm{Ng}$ et al., Yahia et al., modified BET, Mahle, Sun and Chakraborty, and Do et al. models. Figure 9 shows the fitting of isotherm data for PVDC/water pair and Tripolis/water pair with different isotherm models using the HYBRID error evaluation function.

Table 11. $p$-value of an overall and pairwise test of equality of the value of minimum IC using HYBRID error of $n=1000$ bootstrap samples.

\begin{tabular}{cccccccc}
\hline Test & AIC & BIC & AIC & mAIC & AIC3 & CAIC & ABIC \\
\hline Overall & $2.2 \times 10^{-16}$ & $2.2 \times 10^{-16}$ & $2.2 \times 10^{-16}$ & $2.2 \times 10^{-16}$ & $2.2 \times 10^{-16}$ & $2.2 \times 10^{-16}$ & $2.2 \times 10^{-16}$ \\
GAB vs. Mod. BET & $2.0 \times 10^{-14}$ & $2.0 \times 10^{-13}$ & $2.0 \times 10^{-14}$ & $2.0 \times 10^{-12}$ & $2.0 \times 10^{-15}$ & $2.0 \times 10^{-14}$ & $2.0 \times 10^{-14}$ \\
GAB vs. Mod. & $2.0 \times 10^{-15}$ & $2.0 \times 10^{-15}$ & $2.1 \times 10^{-14}$ & $2.2 \times 10^{-15}$ & $2.2 \times 10^{-15}$ & $2.0 \times 10^{-15}$ & $2.1 \times 10^{-15}$ \\
Langmuir & & & & & & \\
\hline
\end{tabular}
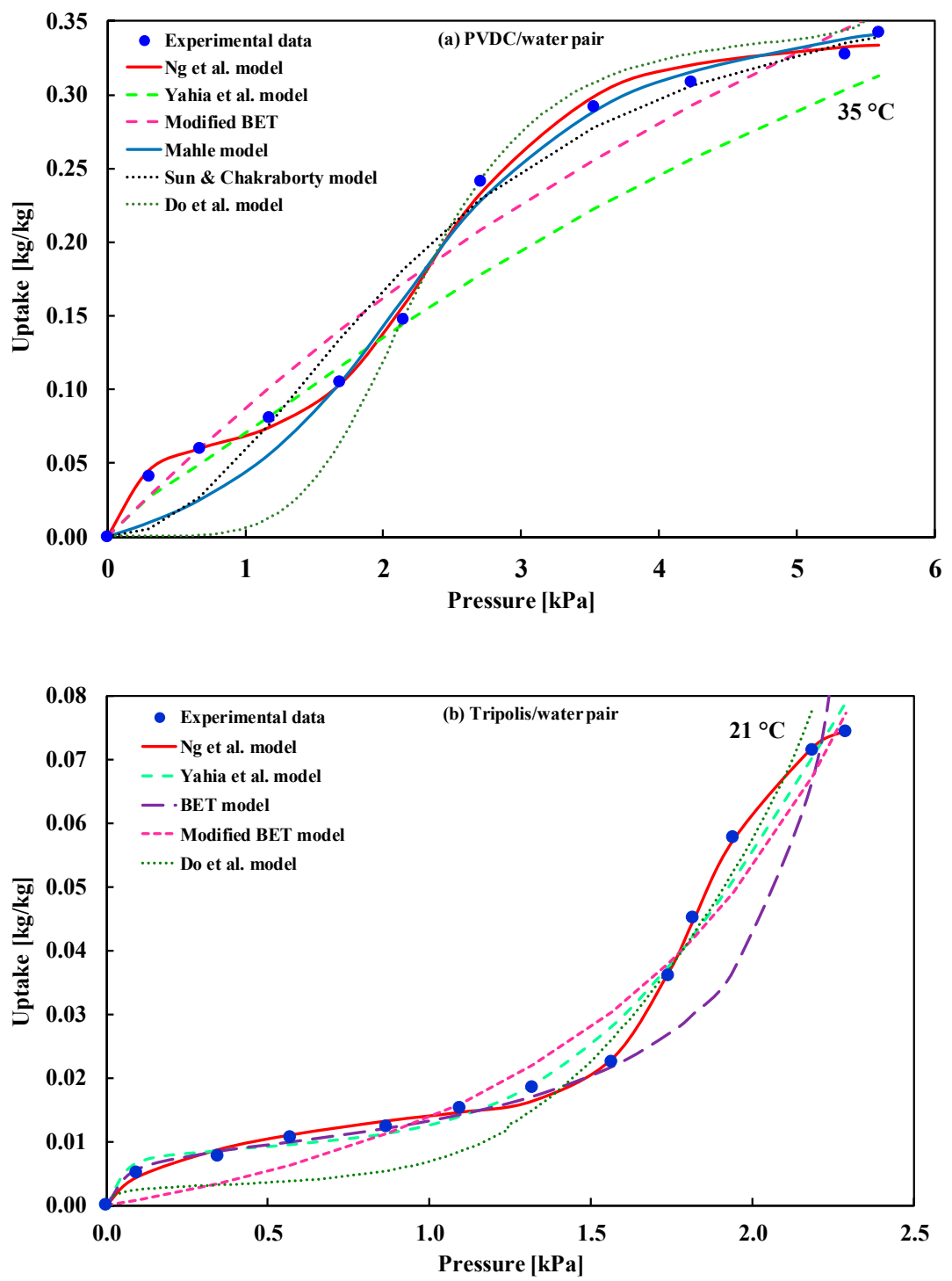

Figure 9. Type-IV(a) adsorption isotherms for (a) PVDC/water pair and (b) Tripolis/water pair. Experimental data are fitted with the $\mathrm{Ng}$ et al., Yahia et al., BET, modified BET, and Do et al. models. 
Mean HYBRID error and 95\% confidence interval of errors are given in Table 12 for adsorption of water onto PVDC and water onto Tripolis pairs. The results indicate that mean error and $95 \%$ CI of the bootstrap samples are small for the $\mathrm{Ng}$ et al. model, as compared to other models. This statement is also checked by determining various information criteria, as presented in Table 13. It is observed that the values of all information criteria, except mAIC, of the $\mathrm{Ng}$ et al. model, are small compared to other probable models, for the adsorption of PVDC/water pair. Since the $\mathrm{Ng}$ et al. model is selected by the majority of the information criterion, so it signifies that considering IC the $\mathrm{Ng}$ et al. model's information loss is less when compared to other models, and the method mAIC is not appropriate in this case. A similar finding is obtained in the case of the adsorption of water onto tripolis.

Table 12. Average and 95\% confidence interval of HYBRID error for $n=1000$ bootstrap samples.

\begin{tabular}{cccccc}
\hline PVDC/Water & Mean Error & $\mathbf{9 5 \%}$ CI of Error & Tripolis/Water & Mean Error & 95\% CI of Error \\
\hline Ng et al. & 0.08324 & $(0.0486,0.1210)$ & Ng et al. & 0.0127 & $(0.0043,0.0247)$ \\
Yahia et al. & 2.69468 & $(1.0143,4.8338)$ & Yahia et al. & 0.0903 & $(0.0341,0.1678)$ \\
Mod. BET & 0.51836 & $(0.2596,0.8222)$ & BET & 0.2576 & $(0.0550,0.5013)$ \\
Mahle & 0.92660 & $(0.1397,1.8578)$ & Mod. BET & 0.1471 & $(0.0613,0.2460)$ \\
Sun and Chakraborty & 1.12546 & $(0.2890,2.1980)$ & Do et al. & 0.4532 & $(0.0043,0.0247)$ \\
\hline
\end{tabular}

Table 13. Optimal isotherm employing model selection criteria using HYBRID error mean of $n=1000$ bootstrap samples.

\begin{tabular}{ccccccccc}
\hline Model & $\begin{array}{c}\text { Mean } \\
\text { Error }\end{array}$ & AIC & BIC & AIC $\boldsymbol{c}_{\boldsymbol{c}}$ & mAIC & AIC3 & CAIC & ABIC \\
\hline Adsorption of water onto PVDC & & & & & & & \\
\hline Ng et al. & 0.08324 & -5.50 & 5.96 & -1.77 & 78.50 & 1.50 & 12.96 & -15.93 \\
Yahia et al. & 2.69468 & 31.27 & 44.37 & 36.24 & 143.27 & 39.27 & 52.37 & 19.36 \\
Mod BET & 0.51836 & 4.79 & 9.70 & 5.49 & 16.79 & 7.79 & 12.70 & 0.32 \\
Mahle & 0.92660 & 12.59 & 19.15 & 13.81 & 36.59 & 16.59 & 23.15 & 6.64 \\
Sun and Chakraborty & 1.12546 & 14.54 & 21.09 & 15.75 & 38.54 & 18.54 & 25.09 & 8.58 \\
\hline Adsorption of water onto Tripolis & & & & & & & \\
\hline Ng et al. & 0.0127 & -34.11 & -22.64 & -30.37 & 49.89 & -27.11 & -15.64 & -44.53 \\
Yahia et al. & 0.0903 & -8.62 & 4.48 & -3.65 & 103.38 & -0.62 & 12.48 & -20.53 \\
BET & 0.2576 & -8.03 & -4.76 & -7.69 & -4.03 & -6.03 & -2.76 & -11.01 \\
Mod BET & 0.1471 & -12.76 & -7.85 & -12.05 & -0.76 & -9.76 & -4.85 & -17.23 \\
\hline
\end{tabular}

* The shaded cells indicate lowest value for a particular information criterion.

\subsection{Type-IV(b) Adsorption Isotherm}

Depending on the pore width, the Type-IV isotherm is divided into two types, one with hysteresis and another without hysteresis, i.e., Type-IV(a) (pore width greater than $4 \mathrm{~nm}$ ) and Type-IV(b) (pore width smaller than $4 \mathrm{~nm}$ ), respectively [14]. Type-IV(b) is observed for the adsorbent having cylindrical and conical mesopores with a smaller width, which are entirely reversible and closed at the tapered end. Type-IV(b) adsorption isotherms are observed for the adsorption of argon at $87 \mathrm{~K}$ and nitrogen at $77 \mathrm{~K}$ onto IRMOF-74-V-hex having pore width less than $4 \mathrm{~nm}$ [36]. In this study, the $\mathrm{Ng}$ et al., modified Langmuir, Mahle, modified BET, and Tóth models are fitted with the experimental data of both pairs and presented in Figure 10. 

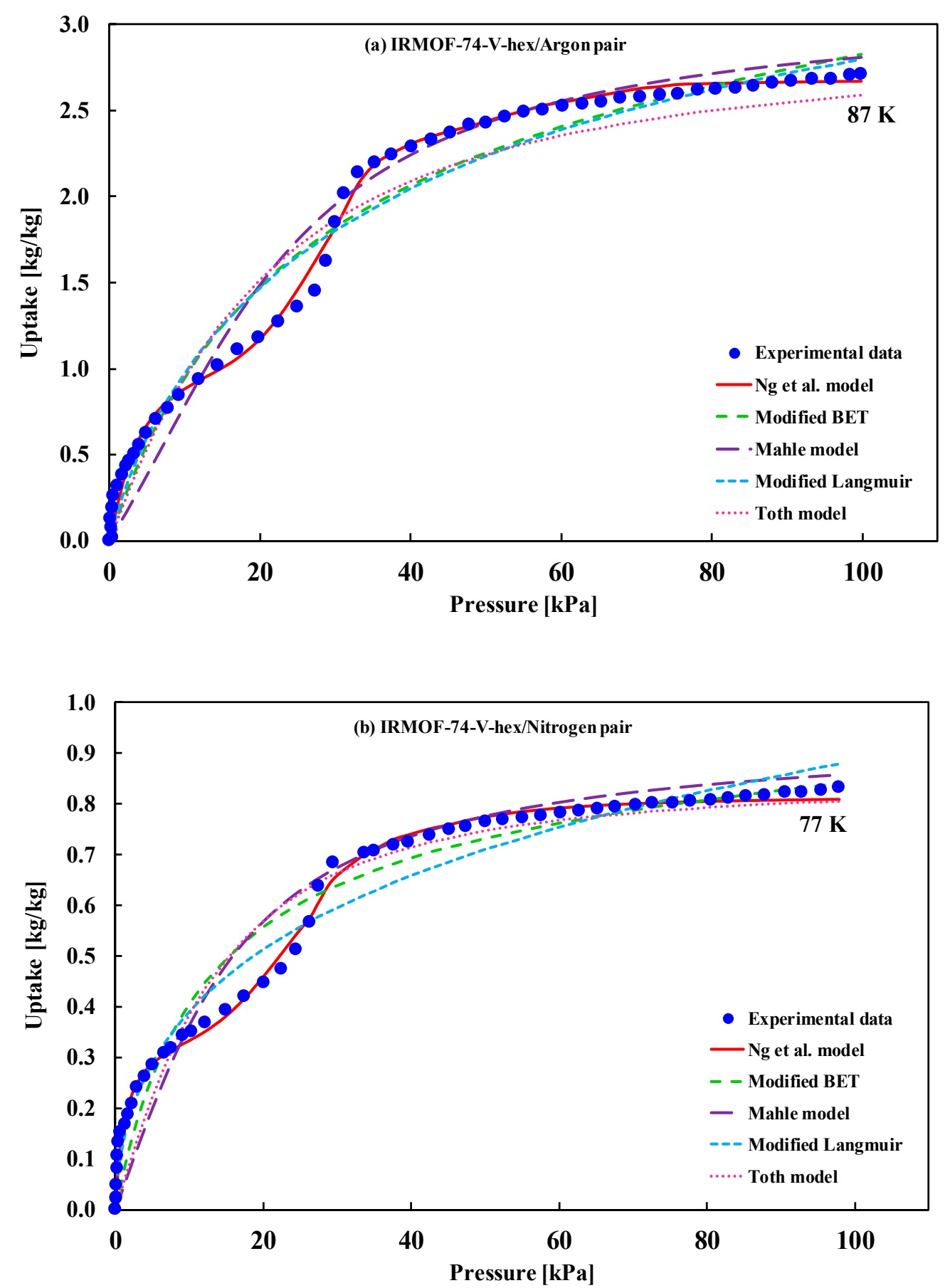

Figure 10. Type-IV(b) adsorption isotherms for (a) IRMOF-74-V-hex/argon pair and (b) IRMOF-74-V-hex/nitrogen pair. Experimental data are fitted with the $\mathrm{Ng}$ et al., modified BET, Mahle, modified Langmuir, and Tóth models.

The HYBRID error means and 95\% CIs of errors are presented in Table 14 for adsorption of argon onto IRMOF-74-V-hex and nitrogen onto IRMOF-74-V-hex pairs. The Ng et al. model has a small amount of error, also confidence interval as compared to other models. This statement is also checked by determining various information criteria, as presented in Table 15. It is also observed that all methods except mAIC select the $\mathrm{Ng}$ et al. model as an optimal for argon adsorption, but nitrogen adsorption, and all ICs select the Ng et al. model. Since the majority of the ICs select the Ng et al. model, it signifies that information loss of the $\mathrm{Ng}$ et al. model is less when compared to other models for Type-IV(b) isotherm. 
Table 14. Average and 95\% confidence interval of HYBRID error for $n=1000$ bootstrap samples.

\begin{tabular}{|c|c|c|c|c|c|}
\hline $\begin{array}{l}\text { IRMOF-74-V- } \\
\text { hex/argon }\end{array}$ & Mean Error & $\begin{array}{c}95 \% \text { CI of } \\
\text { Error }\end{array}$ & $\begin{array}{l}\text { IRMOF-74-V- } \\
\text { hex/nitrogen }\end{array}$ & Mean Error & $\begin{array}{c}95 \% \text { CI of } \\
\text { Error }\end{array}$ \\
\hline Ng et al. & 0.95400 & $\begin{array}{l}(0.8126, \\
0.9967)\end{array}$ & $\mathrm{Ng}$ et al. & 0.18451 & $\begin{array}{l}(0.1124 \\
0.2435)\end{array}$ \\
\hline Mod. BET & 2.71755 & $\begin{array}{l}(1.9571 \\
3.1684)\end{array}$ & Mod. BET & 1.19510 & $\begin{array}{l}(0.5642 \\
2.9856)\end{array}$ \\
\hline Mahle & 4.24836 & $\begin{array}{l}(3.2145, \\
6.2541)\end{array}$ & Mahle & 1.18360 & $\begin{array}{l}(0.4265 \\
3.2113)\end{array}$ \\
\hline Mod. Langmuir & 2.68435 & $\begin{array}{l}(1.2563, \\
4.1256)\end{array}$ & Mod. Langmuir & 0.53406 & $\begin{array}{l}(0.0613 \\
2.1560)\end{array}$ \\
\hline Tóth & 4.34000 & $\begin{array}{l}(3.5671, \\
5.3461)\end{array}$ & Tóth & 1.65845 & $\begin{array}{l}(0.4125 \\
2.6571)\end{array}$ \\
\hline
\end{tabular}

Table 15. Optimal isotherm employing model selection criteria using HYBRID error mean of $n=1000$ bootstrap samples.

\begin{tabular}{|c|c|c|c|c|c|c|c|c|}
\hline Model & Mean Error & $A I C$ & BIC & $A I C_{c}$ & $m A I C$ & AIC3 & CAIC & $A B I C$ \\
\hline \multicolumn{9}{|c|}{ Adsorption of argon onto IRMOF-74-A-hex } \\
\hline Ng et al. & 0.95400 & -48.49 & -37.03 & -44.76 & 35.51 & -41.49 & -30.03 & -58.92 \\
\hline Mod. BET & 2.71755 & -1.01 & 3.90 & -0.31 & 10.99 & 1.99 & 6.90 & -5.48 \\
\hline Mahle & 4.24836 & 24.67 & 31.22 & 25.88 & 48.67 & 28.67 & 35.22 & 18.71 \\
\hline Mod. Langmuir & 2.68435 & 6.34 & 17.80 & 10.07 & 90.34 & 13.34 & 24.80 & -4.09 \\
\hline Tóth & 4.34000 & 25.80 & 32.35 & 27.01 & 49.80 & 29.80 & 36.35 & 19.84 \\
\hline \multicolumn{9}{|c|}{ Adsorption of $\mathrm{N}_{2}$ onto IRMOF-74-A-hex } \\
\hline Ng et al. & 0.18451 & -135.57 & -124.1 & -131.84 & -51.57 & -128.5 & -117.1 & -145.9 \\
\hline Mod. BET & 1.19510 & -44.55 & -39.64 & -43.84 & -32.55 & -41.55 & -36.64 & -49.02 \\
\hline Mahle & 1.18360 & -19.79 & -13.24 & -18.58 & 4.21 & -15.79 & -9.24 & -25.75 \\
\hline Mod. Langmuir & 0.53406 & -79.24 & -67.78 & -75.51 & 4.76 & -72.24 & -60.78 & -89.66 \\
\hline Tóth & 1.65845 & -25.18 & -18.63 & -23.97 & -1.18 & -21.18 & -14.63 & -31.14 \\
\hline
\end{tabular}

* The shaded cells indicate lowest value for a particular information criterion.

\subsection{Type- $V$ Adsorption Isotherm}

Type-V is distinguished by its characteristic S-shaped isotherm, and it also demonstrates a hysteresis loop. Water adsorption onto different types of zeolites exhibits Type-V characteristics. In the present investigation, an AQSOA-Z01/water pair is considered for the analysis of the Type- $\mathrm{V}$ isotherm model. Kayal et al. [37] utilized D-A, modified Langmuir, and Sun and Chakraborty models for the adsorption of water onto AQSOA-Z01 at temperatures $25^{\circ} \mathrm{C}, 40^{\circ} \mathrm{C}$, and $65^{\circ} \mathrm{C}$. The isotherms are fitted in the current study with Sun and Chakraborty, modified Langmuir, Mahle, D-A, and Ng et al. models presented in Figure 11.

The results of bootstrap mean HYBRID error, 95\% CI, and IC values are presented in Table 16. The results show that the mean HYBRID error, $95 \% \mathrm{CI}$ of errors, as well as values of all information criteria are small for Sun and Chakraborty model, as compared to all other models. This indicates that the Sun and Chakraborty model incurs the lowest information loss as compared to all other models taken into consideration.

The selection probabilities of two possible models, namely, the Sun and Chakraborty model and modified Langmuir model, are depicted in Figure 12. It is again evident from the figure that for the adsorption pair in concern, the selection probability of the Sun and Chakraborty model is much higher than that of the modified Langmuir model. The overall and pairwise proportion tests (as presented in Table 17) reveal that the Sun and Chakraborty model has significantly less information loss as compared to a modified Langmuir model. 


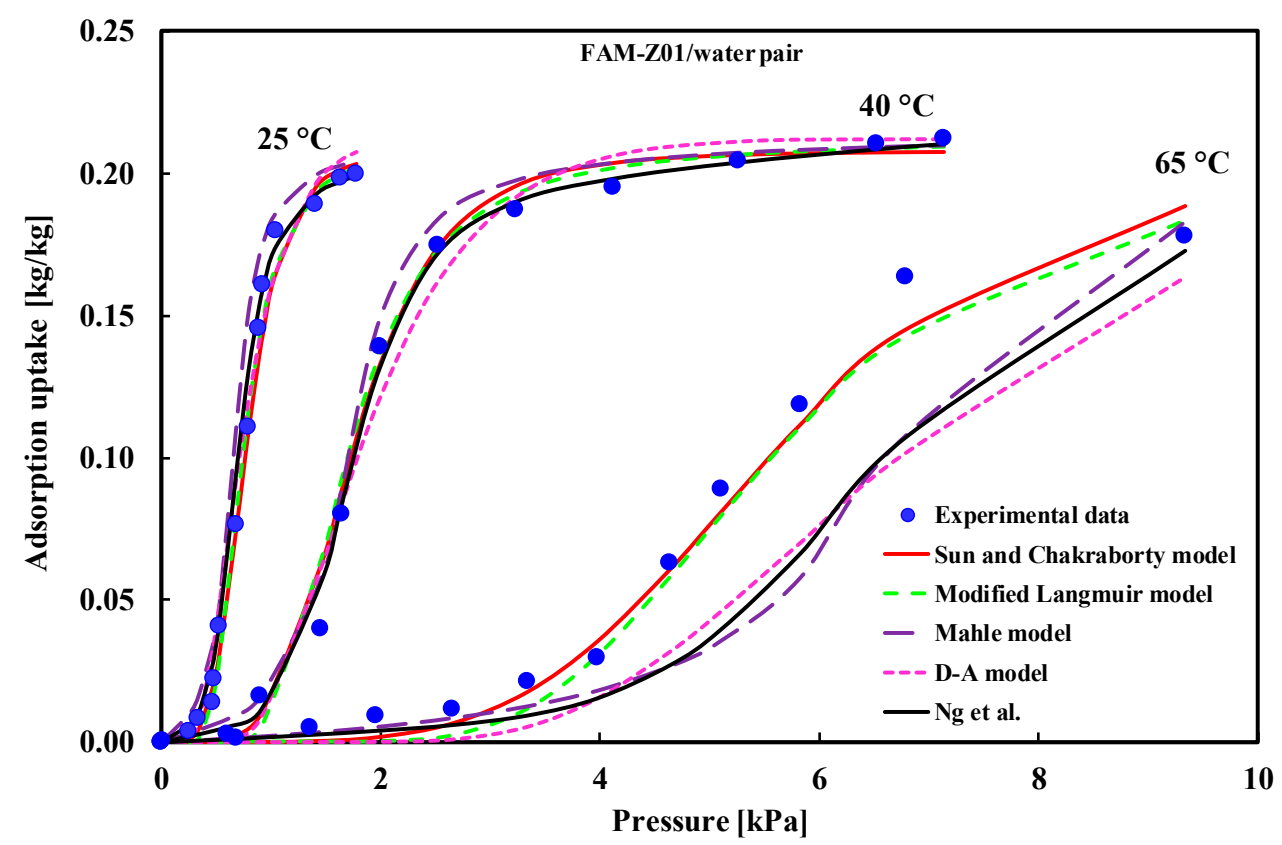

Figure 11. Type-V adsorption isotherm of FAM-Z01/water pair; experimental data are fitted with the Sun and Chakraborty, modified Langmuir, Mahle, D-A, and Ng et al. models using the HYBRID error evaluation function.

Table 16. Optimal isotherm employing model selection criteria using a HYBRID error mean of $n=1000$ bootstrap samples.

\begin{tabular}{cccccccccc}
\hline Model & $\begin{array}{c}\text { Mean } \\
\text { Error }\end{array}$ & $\begin{array}{c}\text { CI of } \\
\text { HYBRID }\end{array}$ & AIC & BIC & AIC & mAIC & AIC3 & CAIC & ABIC \\
\hline D-A & 0.5370 & $\begin{array}{l}(0.3538, \\
0.7506)\end{array}$ & -43.21 & -38.46 & -42.46 & -31.21 & -40.21 & -35.46 & -47.83 \\
Mahle & 0.9121 & $\begin{array}{l}(0.4822, \\
1.4353)\end{array}$ & -22.14 & -15.81 & -20.85 & 1.86 & -18.14 & -11.81 & -28.30 \\
modified & 0.2172 & $\begin{array}{l}(0.1225, \\
0.3370) \\
\text { Langmuir }\end{array}$ & -67.79 & -56.71 & -63.79 & 16.21 & -60.79 & -49.71 & -78.58 \\
GAB & 2.6254 & $\begin{array}{l}(1.9507, \\
3.3515)\end{array}$ & 13.92 & 18.67 & 14.67 & 25.92 & 16.92 & 21.67 & 9.30 \\
Sun and & 0.1453 & $\begin{array}{l}(0.0741, \\
0.2364)\end{array}$ & -88.27 & -81.94 & -86.98 & -64.27 & -84.27 & -77.94 & -94.44 \\
Chakraborty & & & & & & & & & \\
\hline
\end{tabular}

* The shaded cells indicate lowest value for a particular information criterion.

Table 17. $p$-value of the overall and pairwise test of equality of the values of minimum IC using HYBRID error for $n=1000$ bootstrap samples.

\begin{tabular}{cccccccc}
\hline Test & AIC & BIC & AIC & mAIC & AIC3 & CAIC & ABIC \\
\hline Overall & $2.2 \times 10^{-16}$ & $2.2 \times 10^{-16}$ & $2.2 \times 10^{-16}$ & $2.2 \times 10^{-16}$ & $2.2 \times 10^{-16}$ & $2.2 \times 10^{-16}$ & $2.2 \times 10^{-16}$ \\
$\begin{array}{c}\text { Sun and Chakraborty } \\
\text { vs. Mod. Langmuir }\end{array}$ & $2.0 \times 10^{-16}$ & $2.0 \times 10^{-16}$ & $2.0 \times 10^{-16}$ & $2.0 \times 10^{-16}$ & $2.0 \times 10^{-16}$ & $2.0 \times 10^{-16}$ & $2.0 \times 10^{-16}$ \\
\hline
\end{tabular}




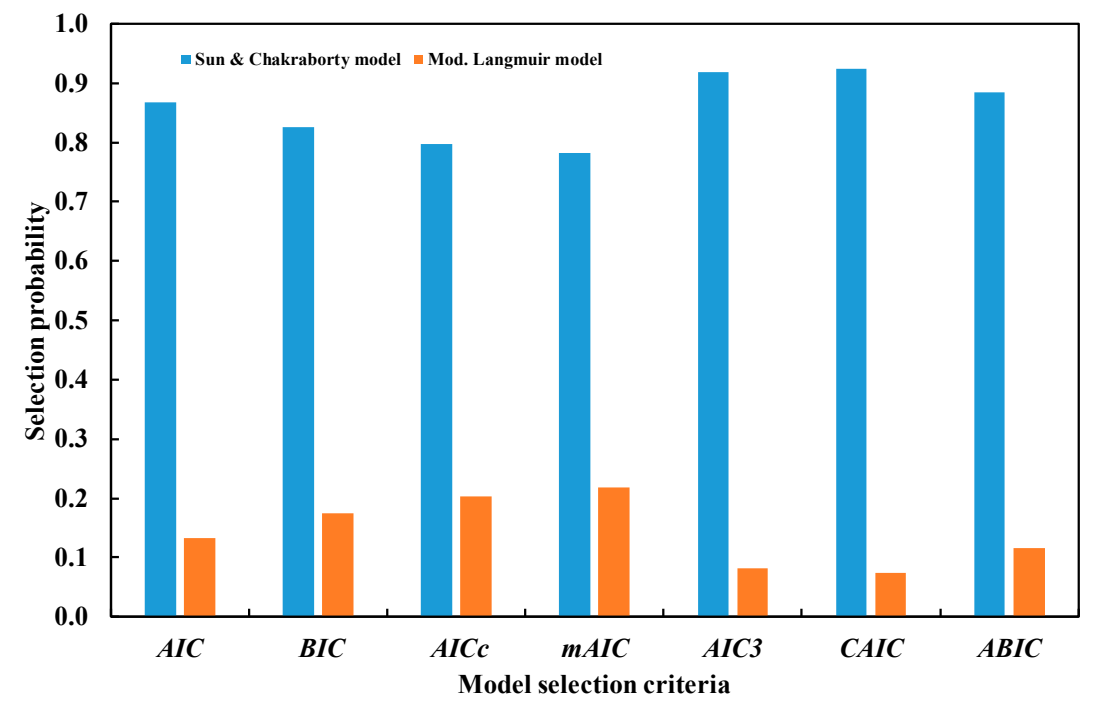

Figure 12. Probability of selecting models for Type-V adsorption isotherms considering different information criteria using HYBRID errors.

\subsection{Type-VI Adsorption Isotherm}

In Type-VI, the adsorption occurs in steps. Two isotherm data are considered in the current study; (i) methane adsorption onto $\mathrm{MgO}$ at $87.4 \mathrm{~K}$ investigated by Gay et al. [75] and (ii) methane onto graphite at 77.3 K examined by Bienfait et al. [76]. These isotherm data are fitted with the Yahia et al., $\mathrm{Ng}$ et al., D-A, modified Langmuir, and Mahle models, and the results are depicted in Figure 13.

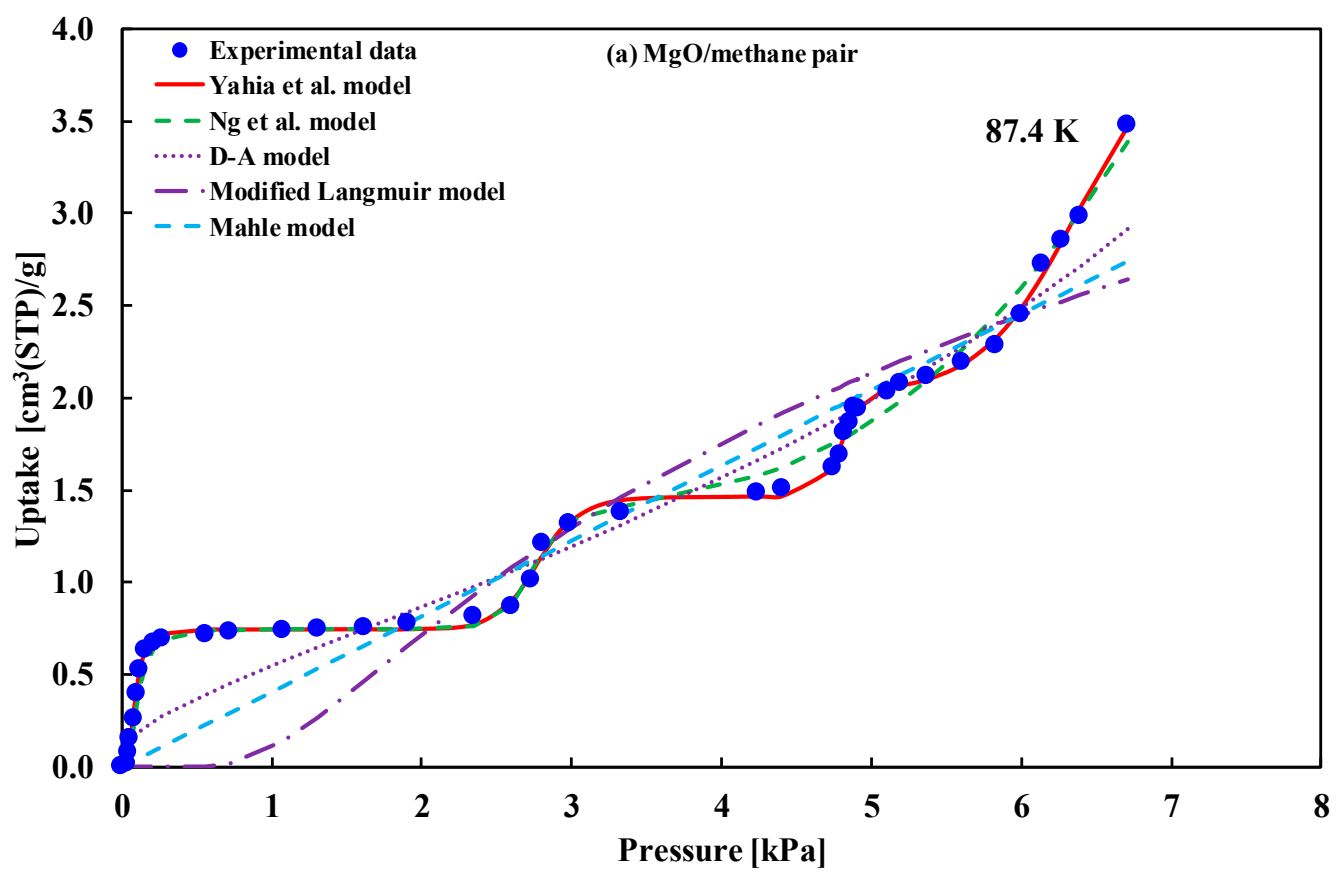

Figure 13. Cont. 


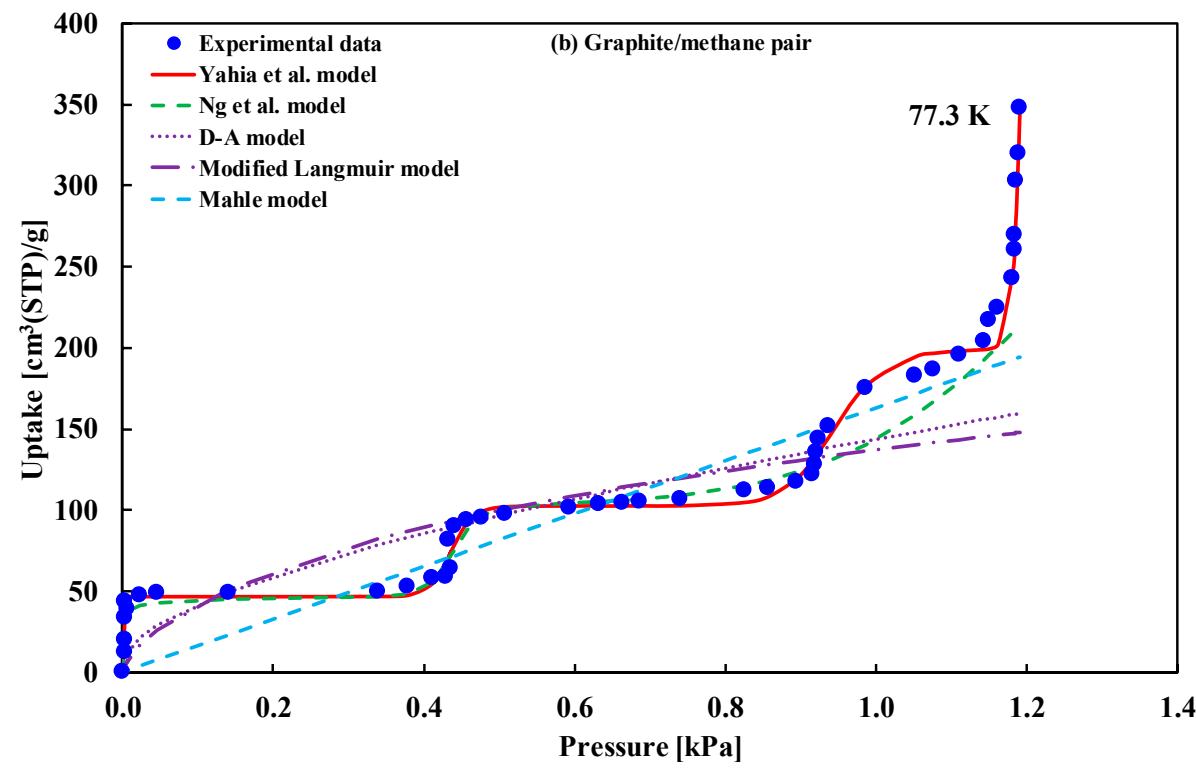

Figure 13. Type-VI adsorption isotherms exhibited by (a) $\mathrm{MgO} /$ methane pair at $87.4 \mathrm{~K}$ and (b) graphite/methane pair at 77.3 K. Experimental data are fitted with the Yahia et al., Ng et al., D-A, modified Langmuir, and Mahle models using the HYBRID error evaluation function.

To further investigate the models, mean HYBRID error and 95\% confidence interval are determined, and the results are presented in Table 18. According to the results, the Yahia et al. model is the preferred model to describe the Type-VI isotherm, as it has the lowest mean error and 95\% CI.

The information criteria are determined for all the models, and results are presented in Table 19. It is observed from the table that, except for mAIC, the values of all IC corresponding to Yahia et al. model are smaller than the other models, and this is true for both the adsorption pairs. Hence, it can be said that the information loss of the Yahia et al. model is less compared to other models.

Table 18. Mean HYBRID error and confidence interval of error for $n=1000$ bootstrap samples.

\begin{tabular}{lccccc}
\hline \multicolumn{1}{c}{ MgO/Methane } & Mean Error & $\mathbf{9 5 \% ~ C I ~ o f ~ E r r o r ~}$ & Graphite/Methane & Mean Error & 95\% CI of Error \\
\hline Yahia et al. & 0.1237 & $(0.0699,0.1835)$ & Yahia et al. & 0.562948 & $(0.3545,0.7757)$ \\
Ng et al. & 0.6007 & $(0.4107,0.7994)$ & Ng et al. & 7.848831 & $(3.4595,13.359)$ \\
D-A & 6.6061 & $(3.4087,10.022)$ & D-A & 15.06557 & $(9.0459,22.345)$ \\
Mod. Langmuir & 21.165 & $(12.654,30.267)$ & Mod. Langmuir & 21.242790 & $(12.848,30.937)$ \\
Mahle & 11.430 & $(6.3491,17.249)$ & Mahle & 12.461560 & $(7.7736,17.705)$ \\
\hline
\end{tabular}

Table 19. Optimal isotherm employing model selection criteria using HYBRID mean error considering $n=1000$ bootstrap samples.

\begin{tabular}{|c|c|c|c|c|c|c|c|c|}
\hline Model & Mean Error & AIC & BIC & $A I C_{c}$ & $m A I C$ & AIC3 & CAIC & $A B I C$ \\
\hline \multicolumn{9}{|c|}{ Adsorption of methane onto $\mathrm{MgO}$} \\
\hline Yahia et al. & 0.1237 & -89.70 & -69.73 & -77.70 & 174.30 & -77.70 & -57.73 & -107.27 \\
\hline Ng et al. & 0.6007 & -26.06 & -4.43 & -11.50 & 285.94 & -13.06 & 8.57 & -45.10 \\
\hline $\mathrm{D}-\mathrm{A}$ & 6.6061 & 47.45 & 52.44 & 48.13 & 59.45 & 50.45 & 55.44 & 43.05 \\
\hline Mod. Langmuir & 21.1652 & 100.86 & 112.50 & 104.47 & 184.86 & 107.86 & 119.50 & 90.60 \\
\hline Mahle & 11.4302 & 70.83 & 77.48 & 72.00 & 94.83 & 74.83 & 81.48 & 64.97 \\
\hline \multicolumn{9}{|c|}{ Adsorption of methane onto graphite } \\
\hline Yahia et al. & 56.29480 & 159.73 & 181.14 & 169.79 & 423.73 & 171.73 & 193.14 & 143.53 \\
\hline $\mathrm{Ng}$ et al. & 784.88310 & 277.66 & 300.86 & 289.80 & 589.66 & 290.66 & 313.86 & 260.12 \\
\hline $\mathrm{D}-\mathrm{A}$ & 1506.55700 & 286.35 & 291.71 & 286.95 & 298.35 & 289.35 & 294.71 & 282.31 \\
\hline Mod. Langmuir & 2124.27900 & 309.47 & 321.96 & 312.58 & 393.47 & 316.47 & 328.96 & 300.03 \\
\hline Mahle & 1246.15600 & 280.00 & 287.14 & 281.03 & 304.00 & 284.00 & 291.14 & 274.61 \\
\hline
\end{tabular}

* The shaded cells indicate lowest value for a particular information criterion. 


\section{Conclusions}

In this study, relevant adsorption pairs for all of the IUPAC-classified adsorption isotherms are analyzed. The experimental isotherm data are fitted with 15 different isotherm models through generalized reduced gradient (GRG) non-linear optimization methods. Selected adsorption pairs have the same properties and curve patterns as their corresponding types. Here, one relevant adsorption pair data with more than one temperatures is considered for Type-I(b), Type-III, and Type-V; and two different relevant adsorption pairs with single temperature are considered for Type-I(a), Type-II, Type-IV(a), Type-IV(b), and Type-VI isotherms. The result of this study gives a clear insight into which model is suitable for a particular adsorption isotherm type. From the rigorous analysis of information criteria using bootstrap mean error, the present study confirms that the modified BET is suitable for Type-I(a) and Type-II; the Tóth model for Type-I(b); the GAB model for Type-III; the Ng et al. for Type-IV(a) and Type IV(b); the Sun and Chakraborty model for Type-V; and the Yahia et al. model for Type-VI, are the optimal models for the viewpoint of information losses. This study reveals that the $95 \%$ confidence intervals of the optimal isotherm models are smaller, and selection probabilities of the optimal isotherm models are more significant compared to the other isotherm models. The negligible $p$-value (close to zero) for overall and pairwise proportion test corresponding to each IUPAC-classified adsorption isotherm confirms that the models stated above as optimal are significantly favorable from the statistical standpoint, and the optimal model could also be applicable for other examples of a particular type. Therefore, the present study provides a universal approach for selecting the optimal model for any types of experimental data on adsorption isotherms. Researchers can use this approach to select the optimal isotherm model after plotting and matching their raw data with any of the eight types of IUPAC-classified isotherms. This will reduce the working hours as well as enhance the reliability of their analysis.

Author Contributions: Conceptualization, M.M.R. and B.B.S.; Formal analysis, M.M.R. and M.M.; Investigation, M.M.R., B.B.S. and A.P.; Methodology, M.M.R. and A.Z.S.; Supervision, B.B.S.; Validation, M.M.R., A.P. and A.Z.S.; Writing-original draft, M.M.R. and M.M.; Correction and revision of manuscript, M.M.R., A.P., A.Z.S. and B.B.S.

Funding: This research received no external funding.

Acknowledgments: The authors would like to thank Md. Amirul Islam and Shamal Chandra Karmaker from Kyushu University, Japan, for their help and suggestion.

Conflicts of Interest: The authors proclaim no conflict of interest.

\section{Abbreviations}

$\begin{array}{ll}\text { ABIC } & \text { adjusted bayesian information criterion } \\ \text { ACF } & \text { activated carbon fiber } \\ \text { ACP } & \text { activated carbon powder } \\ \text { AHT } & \text { adsorption heat transformation } \\ \text { AIC } & \text { akaike information criterion } \\ \text { AIC } & \text { corrected akaike information criterion } \\ \text { BET } & \text { brunauer-emmet-teller } \\ \text { BIC } & \text { bayesian information criterion } \\ \text { BIDC } & \text { benzimidazole-derived carbons } \\ \text { CI } & \text { confidence interval } \\ \text { D-A } & \text { dubinin-astakhov } \\ \text { GAB } & \text { guggenheim-anderson-de boer } \\ \text { GRG } & \text { generalized reduced gradient } \\ \text { IC } & \text { information criterion } \\ \text { IRMOF } & \text { isoreticular metal-organic framework } \\ \text { IUPAC } & \text { international union of pure and applied chemistry } \\ \text { M-AC } & \text { mangrove based activated carbon } \\ \text { mAIC } & \text { modified akaike information criterion } \\ \text { MgO } & \text { magnesium oxide }\end{array}$


PBA polymer based adsorbent

PCB poorly crystalline boehmite

PVDC polyvinylidene chloride

RMSD root-mean-square deviation

RSS residual sum of squares

WPT waste palm trunk

\section{References}

1. Grekova, A.; Gordeeva, L.; Sapienza, A.; Aristov, Y. Adsorption transformation of heat: The applicability in various climatic zones of the Russian federation. Appl. Sci. 2019, 9, 139. [CrossRef]

2. Saha, B.B.; Koyama, S.; Kashiwagi, T.; Akisawa, A.; Ng, K.C.; Chua, H.T. Waste heat driven dual-mode, multi-stage, multi-bed regenerative adsorption system. Int. J. Refrig. 2003, 26, 749757. [CrossRef]

3. Palomba, V.; Aprile, M.; Motta, M.; Vasta, S. Study of sorption systems for application on low-emission fishing vessels. Energy 2017, 134, 554-565. [CrossRef]

4. Ng, K.C.; Thu, K.; Saha, B.B.; Chakraborty, A. Study on a waste heat-driven adsorption cooling cum desalination cycle. Int. J. Refrig. 2012, 35, 685-693. [CrossRef]

5. Chakraborty, A.; Saha, B.B.; Aristov, Y.I. Dynamic behaviors of adsorption chiller: Effects of the silica gel grain size and layers. Energy 2014, 78, 304-312. [CrossRef]

6. Pal, A.; Uddin, K.; Thu, K.; Saha, B.B. Activated carbon and graphene nanoplatelets based novel composite for performance enhancement of adsorption cooling cycle. Energy Convers. Manag. 2019, 180, 134-148. [CrossRef]

7. Chalaev, D.M.; Aristov, Y.I. Assessment of the operation of a low-temperature adsorption refrigerator. Therm. Eng. 2006, 53, 240-244. [CrossRef]

8. Balaras, C.A.; Grossman, G.; Henning, H.-M.; Ferreira, C.A.I.; Podesser, E.; Wang, L.; Wiemken, E. Solar air conditioning in Europe-An overview. Renew. Sustain. Energy Rev. 2007, 11, 299-314. [CrossRef]

9. Saha, B.B.; El-Sharkawy, I.I.; Shahzad, M.W.; Thu, K.; Ang, L.; Ng, K.C. Fundamental and application aspects of adsorption cooling and desalination. Appl. Therm. Eng. 2016, 97, 68-76. [CrossRef]

10. Jaiswal, A.K.; Mitra, S.; Dutta, P.; Srinivasan, K.; Srinivasa Murthy, S. Influence of cycle time and collector area on solar driven adsorption chillers. Sol. Energy 2016, 136, 450-459. [CrossRef]

11. Solovyeva, M.V.; Gordeeva, L.G.; Aristov, Y.I. "MIL-101(Cr)-methanol” as working pair for adsorption heat transformation cycles: Adsorbent shaping, adsorption equilibrium and dynamics. Energy Convers. Manag. 2019, 182, 299-306. [CrossRef]

12. Tamainot-Telto, Z.; Metcalf, S.J.; Critoph, R.E.; Zhong, Y.; Thorpe, R. Carbon-ammonia pairs for adsorption refrigeration applications: Ice making, air conditioning and heat pumping. Int. J. Refrig. 2009, 32, 1212-1229. [CrossRef]

13. Sing, K.S.W. Reporting physisorption data for gas/solid systems with special reference to the determination of surface area and porosity (Recommendations 1984). Pure Appl. Chem. 1985, 57, 603-619. [CrossRef]

14. Thommes, M.; Kaneko, K.; Neimark, A.V.; Olivier, J.P.; Rodriguez-Reinoso, F.; Rouquerol, J.; Sing, K.S.W. Physisorption of gases, with special reference to the evaluation of surface area and pore size distribution (IUPAC Technical Report). Pure Appl. Chem. 2015, 87, 1051-1069. [CrossRef]

15. Muttakin, M.; Mitra, S.; Thu, K.; Ito, K.; Saha, B.B. Theoretical framework to evaluate minimum desorption temperature for IUPAC classified adsorption isotherms. Int. J. Heat Mass Transf. 2018, 122, 795-805. [CrossRef]

16. Ng, K.C.; Burhan, M.; Shahzad, M.W.; Ismail, A. Bin A Universal Isotherm Model to Capture Adsorption Uptake and Energy Distribution of Porous Heterogeneous Surface. Sci. Rep. 2017, 7, 10634. [CrossRef]

17. Saha, B.B.; Uddin, K.; Pal, A.; Thu, K. Emerging sorption pairs for heat pump applications: An overview. JMST Adv. 2019, 1, 161-180. [CrossRef]

18. Hu, X.; Radosz, M.; Cychosz, K.A.; Thommes, $\mathrm{M}$. $\mathrm{CO}_{2}$-filling capacity and selectivity of carbon nanopores: Synthesis, texture, and pore-size distribution from quenched-solid density functional theory (QSDFT). Environ. Sci. Technol. 2011, 45, 7068-7074. [CrossRef]

19. Cychosz, K.A.; Thommes, M. Progress in the Physisorption Characterization of Nanoporous Gas Storage Materials. Engineering 2018, 4, 559-566. [CrossRef] 
20. El-Sharkawy, I.I.; Uddin, K.; Miyazaki, T.; Saha, B.B.; Koyama, S.; Miyawaki, J.; Yoon, S.-H.H. Adsorption of ethanol onto parent and surface treated activated carbon powders. Int. J. Heat Mass Transf. 2014, 73, 445-455. [CrossRef]

21. Rahman, M.M.; Pal, A.; Uddin, K.; Thu, K.; Saha, B.B. Statistical Analysis of Optimized Isotherm Model for Maxsorb III/Ethanol and Silica Gel/Water Pairs. Evergreen 2018, 5, 1-12. [CrossRef]

22. Pal, A.; El-Sharkawy, I.I.; Saha, B.B.; Jribi, S.; Miyazaki, T.; Koyama, S. Experimental investigation of $\mathrm{CO}_{2}$ adsorption onto a carbon based consolidated composite adsorbent for adsorption cooling application. Appl. Therm. Eng. 2016, 109, 304-311. [CrossRef]

23. Pal, A.; Kil, H.S.; Mitra, S.; Thu, K.; Saha, B.B.; Yoon, S.H.; Miyawaki, J.; Miyazaki, T.; Koyama, S. Ethanol adsorption uptake and kinetics onto waste palm trunk and mangrove based activated carbons. Appl. Therm. Eng. 2017, 122, 389-397. [CrossRef]

24. Pal, A.; Thu, K.; Mitra, S.; El-Sharkawy, I.I.; Saha, B.B.; Kil, H.S.; Yoon, S.H.; Miyawaki, J. Study on biomass derived activated carbons for adsorptive heat pump application. Int. J. Heat Mass Transf. 2017, 110, 7-19. [CrossRef]

25. Wang, Y.; LeVan, M.D. Adsorption equilibrium of carbon dioxide and water vapor on zeolites 5a and $13 \mathrm{X}$ and silica gel: Pure components. J. Chem. Eng. Data 2009, 54, 2839-2844. [CrossRef]

26. Brancato, V.; Frazzica, A.; Sapienza, A.; Gordeeva, L.; Freni, A. Ethanol adsorption onto carbonaceous and composite adsorbents for adsorptive cooling system. Energy 2015, 84, 177-185. [CrossRef]

27. Berdenova, B.; Pal, A.; Muttakin, M.; Mitra, S.; Thu, K.; Saha, B.B.; Kaltayev, A. A comprehensive study to evaluate absolute uptake of carbon dioxide adsorption onto composite adsorbent. Int. J. Refrig. 2019, 100, 131-140. [CrossRef]

28. Pal, A.; Shahrom, M.S.R.; Moniruzzaman, M.; Wilfred, C.D.; Mitra, S.; Thu, K.; Saha, B.B. Ionic liquid as a new binder for activated carbon based consolidated composite adsorbents. Chem. Eng. J. 2017, 326, 980-986. [CrossRef]

29. Younes, M.M.; El-sharkawy, I.I.; Kabeel, A.E.; Uddin, K.; Pal, A.; Mitra, S.; Thu, K.; Saha, B.B. Synthesis and characterization of silica gel composite with polymer binders for adsorption cooling applications. Int. J. Refrig. 2019, 98, 161-170. [CrossRef]

30. Sultan, M.; Miyazaki, T.; Koyama, S. Optimization of adsorption isotherm types for desiccant air-conditioning applications. Renew. Energy 2018, 121, 441-450. [CrossRef]

31. Naono, H.; Hakuman, M. Analysis of adsorption isotherms of water vapor for nonporous and porous adsorbents. J. Colloid Interface Sci. 1991, 145, 405-412. [CrossRef]

32. Wang, S.L.; Johnston, C.T.; Bish, D.L.; White, J.L.; Hem, S.L. Water-vapor adsorption and surface area measurement of poorly crystalline boehmite. J. Colloid Interface Sci. 2003, 260, 26-35. [CrossRef]

33. Maroulis, Z.B.; Tsami, E.; Marinos-Kouris, D.; Saravacos, G.D. Application of the GAB model to the moisture sorption isotherms for dried fruits. J. Food Eng. 1988, 7, 63-78. [CrossRef]

34. Do, D.D.; Do, H.D. Model for water adsorption in activated carbon. Carbon 2000, 38, 767-773. [CrossRef]

35. Volkova, V.; Kiose, T.; Golubchik, K.; Rakitskaya, T.; Baumer, V. Effect of Both the Phase Composition and Modification Methods on Structural-Adsorption Parameters of Dispersed Silicas. Colloids Interfaces 2018, 3, 1.

36. Cho, H.S.; Yang, J.; Gong, X.; Zhang, Y.B.; Momma, K.; Weckhuysen, B.M.; Deng, H.; Kang, J.K.; Yaghi, O.M.; Terasaki, O. Isotherms of individual pores by gas adsorption crystallography. Nat. Chem. 2019, 11, 562-570. [CrossRef]

37. Kayal, S.; Baichuan, S.; Saha, B.B. Adsorption characteristics of AQSOA zeolites and water for adsorption chillers. Int. J. Heat Mass Transf. 2016, 92, 1120-1127. [CrossRef]

38. Kim, Y.D.; Thu, K.; Ng, K.C. Adsorption characteristics of water vapor on ferroaluminophosphate for desalination cycle. Desalination 2014, 344, 350-356. [CrossRef]

39. Teo, H.W.B.; Chakraborty, A.; Fan, W. Improved adsorption characteristics data for AQSOA types zeolites and water systems under static and dynamic conditions. Microporous Mesoporous Mater. 2017, 242, 109-117.

40. Brancato, V.; Frazzica, A. Characterisation and comparative analysis of zeotype water adsorbents for heat transformation applications. Sol. Energy Mater. Sol. Cells 2018, 180, 91-102. [CrossRef]

41. Yahia, M.B.; Khalfaoui, M.; Hachicha, M.A.; Lamine, A.B.; Torkia, Y.B.; Knani, S. Models for Type VI Adsorption Isotherms from a Statistical Mechanical Formulation. Adsorpt. Sci. Technol. 2013, 31, 341-357. [CrossRef] 
42. Rocky, K.A.; Pal, A.; Moniruzzaman, M.; Saha, B.B. Adsorption characteristics and thermodynamic property fields of polymerized ionic liquid and polyvinyl alcohol based composite/ $\mathrm{CO}_{2}$ pairs. J. Mol. Liq. 2019, 294, 111555. [CrossRef]

43. Astakhov, V.A.; Dubinin, M.M. Development of the concept of volume filling of micropores in the adsorption of gases and vapors by microporous adsorbents-Communication 3. Zeolites with large cavities and a substantial number of adsorption centers. Bull. Acad. Sci. USSR Div. Chem. Sci. 1971, 20, 13-16. [CrossRef]

44. Do, D.D. Adsorption Analysis: Equilibria and Kinetics: (With CD Containing Computer Matlab Programs); Imperial College Press: London, UK, 1998; Volume 2, ISBN 978-1-78326-224-3.

45. Amankwah, K.A.G.; Schwarz, J.A. A modified approach for estimating pseudo-vapor pressures in the application of the Dubinin-Astakhov equation. Carbon 1995, 33, 1313-1319. [CrossRef]

46. Pal, A.; Uddin, K.; Rocky, K.A.; Thu, K.; Saha, B.B. $\mathrm{CO}_{2}$ adsorption onto activated carbon-graphene composite for cooling applications. Int. J. Refrig. 2019, 106, 558-569. [CrossRef]

47. Ozawa, S.; Kusumi, S.E.I.I.C.H.I.R.O.; Ogino, Y. 1976-OzawaKusumiOgino-Physical adsorption of gases at high pressure. IV. An improvement of the Dubinin-Astakhov adsorption equation. J. Colloid Interface Sci. 1976, 56, 83-91. [CrossRef]

48. Jribi, S.; Miyazaki, T.; Saha, B.B.; Pal, A.; Younes, M.M.; Koyama, S.; Maalej, A. Equilibrium and kinetics of CO 2 adsorption onto activated carbon. Int. J. Heat Mass Transf. 2017, 108, 1941-1946. [CrossRef]

49. Liu, Z.; Zhang, Z.; Liu, X.; Wu, T.; Du, X. Supercritical $\mathrm{CO}_{2}$ Exposure-Induced Surface Property, Pore Structure, and Adsorption Capacity Alterations in Various Rank Coals. Energies 2019, 12, 3294. [CrossRef]

50. Zou, J.; Rezaee, R. A prediction model for methane adsorption capacity in shale gas reservoirs. Energies 2019, 12, 280. [CrossRef]

51. Wanassi, B.; Hariz, I.B.; Ghimbeu, C.M.; Vaulot, C.; Jeguirim, M. Green carbon composite-derived polymer resin and waste cotton fibers for the removal of alizarin red S dye. Energies 2017, 10, 1321. [CrossRef]

52. Foo, K.Y.; Hameed, B.H. Insights into the modeling of adsorption isotherm systems. Chem. Eng. J. 2010, 156, 2-10. [CrossRef]

53. Mahle, J.J. An adsorption equilibrium model for Type 5 isotherms. Carbon 2002, 40, 2753-2759. [CrossRef]

54. Sun, B.; Chakraborty, A. Thermodynamic formalism of water uptakes on solid porous adsorbents for adsorption cooling applications. Appl. Phys. Lett. 2014, 104, 201901. [CrossRef]

55. Hogg, R.V.; Tanis, E.A.; Zimmerman, D.L. Probability and Statistical Interference; Pearson Education, Inc.: Fort Worth, TX, USA, 2003; ISBN 9780133936544.

56. Porter, J.F.; McKay, G.; Choy, K.H. The prediction of sorption from a binary mixture of acidic dyes using single- and mixed-isotherm variants of the ideal adsorbed solute theory. Chem. Eng. Sci. 1999, 54, 5863-5885. [CrossRef]

57. Sclove, L.S. Application of model selection criteria to some problems in multivariate analysis. Psychometrika 1987, 52, 333-343. [CrossRef]

58. Koukouvinos, C.; Mylona, K.; Skountzou, A. A variable selection method for analyzing supersaturated designs. Commun. Stat. Simul. Comput. 2011, 40, 484-496. [CrossRef]

59. Dziak, J.J.; Coffman, D.L.; Lanza, S.T.; Li, R. Sensitivity and Specificity of Information Criteria. Peer J. Prepr. 2015, 1-20. [CrossRef]

60. Akaike, H. Fitting Autoregressive Models for Prediction. Ann. Inst. Stat. Math. 1969, 21, 243-247. [CrossRef]

61. Bozdogan, H. Model selection and Akaike's Information Criterion (AIC): The general theory and its analytical extensions. Psychometrika 1987, 52, 345-370. [CrossRef]

62. Kamruzzaman, M.; Khudri, M.M.; Rahman, M.M. Modeling and Predicting Stock Market Returns: A Case Study on Dhaka Stock Exchange of Bangladesh. Dhaka Univ. J. Sci. 2017, 65, 97-101.

63. Kullback, S.; Leibler, R.A. On Information and Sufficiency. Ann. Math. Stat. 2010, 22, 79-86. Available online: http://www.jstor (accessed on 15 November 2019). [CrossRef]

64. Hurvich, C.M.; Tsai, C.-L. Regression and Time Series Model Selection in Small Samples. Biometrika 1989, 76, 297-307. [CrossRef]

65. Sugiura, N. Further analysts of the data by akaike' s information criterion and the finite corrections. Commun. Stat. Theory Methods 1978, 7, 13-26. [CrossRef]

66. Burnham, K.P.; Anderson, D.R. Multimodel Inference. Sociol. Methods Res. 2004, 33, 261-304. [CrossRef]

67. Anderson, D.B.K. Model Selection and Multimodel Inference; Springer: New York, NY, USA, 2002; p. 515. 
68. Phoa, F.K.H.; Pan, Y.H.; Xu, H. Analysis of supersaturated designs via the Dantzig selector. J. Stat. Plan. Inference 2009, 139, 2362-2372. [CrossRef]

69. Schwarz, G. Estimating the Dimension of a Model. Ann. Stat. 1978, 6, 461-464. [CrossRef]

70. Rissanen, J. Modeling by shortest data description. Automatica 1978, 14, 465-471. [CrossRef]

71. Boekee, D.E.; Buss, H.H. Order estimation of autoregressive models. In Proceedings of the 4th Aachen Colloquium: Theory and Application of Signal Processing, Aachen, Germany, 1981; pp. 126-130.

72. Efron, B.; Tibshirani, R.J. Introduction to the Bootstrap; Springer: Toronto, ON, Canada, 1993; ISBN 9780412042317.

73. Joshi, M.; Kremling, A.; Seidel-Morgenstern, A. Model based statistical analysis of adsorption equilibrium data. Chem. Eng. Sci. 2006, 61, 7805-7818. [CrossRef]

74. Saha, S.K.; Haque, M.E.; Islam, D.; Rahman, M.M.; Islam, M.R.; Parvin, A.; Rahman, S. Comparative study between the effect of Momordica charantia (wild and hybrid variety) on hypoglycemic and hypolipidemic activity of alloxan induced type 2 diabetic long-evans rats. J. Diabetes Mellit. 2012, 2, 133-137. [CrossRef]

75. Gay, J.M.; Suzanne, J. Wetting, surface melting, and freezing of thin films of methane adsorbed on $\mathrm{MgO}(100)$. Am. Phys. Soc. 1990, 41, 346-351. [CrossRef]

76. Bienfait, M.; Zeppenfeld, P.; Gay, J.M.; Palmari, J.P. Surface melting on the close-packed (111) face of methane thin films condensed on graphite. Surf. Sci. 1990, 226, 327-338. [CrossRef]

(C) 2019 by the authors. Licensee MDPI, Basel, Switzerland. This article is an open access article distributed under the terms and conditions of the Creative Commons Attribution (CC BY) license (http://creativecommons.org/licenses/by/4.0/). 